\title{
Explotación de guanacos por cazadores- recolectores durante el Holoceno medio en la costa sur de Tierra del Fuego (Argentina)
}

Daniela V. Alunni*, Martín Vázquez y Atilio F. Zangrando*
Recibido:

10 de marzo de 2019

Aceptado:

7 de agosto de 2019

\section{Resumen}

En este trabajo se discuten los modos de explotación de guanacos (Lama guanicoe) por cazadores-recolectores costeros que habitaron el litoral sur de Tierra del Fuego durante el Holoceno medio. Este período constituyó un momento clave en el proceso de poblamiento humano del archipiélago fueguino, dado que se propuso como escenario inicial de una adaptación al ambiente de canales e islas del extremo sur americano. En este contexto, se evalúan las estrategias de aprovisionamiento de guanacos y el rol que pudieron haber tenido los espacios terrestres para la economía de los cazadoresrecolectores y pescadores que ocuparon estos espacios. Para ello, se analizan y comparan tres conjuntos arqueológicos correspondientes a ese período pero ubicados en entornos ambientales disímiles y que ofrecen distintas condiciones para la captura y transporte de guanacos. Los resultados muestran que estas prácticas se desarrollaron bajo estrategias diferentes según cada sector, y que esta variabilidad no necesariamente estuvo relacionada con las disposiciones espaciales y estacionales alternantes que presenta el recurso, sino también con diversas contingencias o requerimientos nutricionales de los grupos humanos que habitaron estas costas durante el Holoceno medio.

\section{Hunter-gatherers' guanaco exploitation during the Middle Holocene in the south coast of Tierra del Fuego (Argentina)}

\begin{abstract}
We analyze the exploitation strategies of guanacos (Lama guanicoe) by the coastal hunter-gatherers that inhabited the southern coast of Tierra del Fuego during the Middle Holocene. This period is considered to be a pivotal moment in the process of human colonization in the Fuegian archipelago, as it was proposed as the initial stage of human adaptation to the channel and island environment at the southernmost tip of the Americas. In this context, we evaluate guanacos' hunting strategies and the role of terrestial environments for hunther-gatherers' subsistence. We analyze and compare three archaeological assemblages corresponding to the Middle Holocene, located in different environments regarding their conditions for the transport and butchering of
\end{abstract}

\section{Keywords}

Coastal hunter-gatherers Transport and butchering Environmental variability 
guanacos. The results show that hunting behaviors developed under different strategies according to each sector. This variability was not necessarily related to the differences in spatial and seasonal distribution of the resource, but to dissimilar contingencies or nutritional requirements of the human groups that inhabited these coasts during the Middle Holocene.

\section{Introducción}

El Holoceno medio constituye un período clave en el proceso de poblamiento humano del archipiélago fueguino, dado que se propuso como escenario inicial de una adaptación al ambiente de canales e islas del extremo sur americano (Legoupil y Fontugne, 1997; Ocampo y Rivas, 2004; Orquera y Piana, 1986-1987, 1988, 1999; Zangrando, Tessone y Vázquez, 2009). En efecto, las evidencias arqueológicas más tempranas que exhiben un estilo de vida plenamente adaptado al litoral provienen de la costa sur de Tierra del Fuego y se remontan a los 6400-5000 años AP, momento para el cual se propuso un escenario de alta especialización en la captura de pinnípedos (Orquera y Piana, 1999). Dicha adaptación fue definida, no sólo por una mayor dependencia al consumo de recursos marinos (particularmente pinnípedos), sino también por el uso de materias primas que proporcionan diferentes especies litorales (como los cetáceos, las aves y los pinnípedos), así como por un desarrollo tecnológico especializado y orientado a optimizar las posibilidades de aprovisionamiento de estos animales en el mar, como arpones y canoas (Orquera y Piana, 1999). Existen buenas razones que fundamentan esta tendencia inicial hacia la explotación de otáridos, las cuales no sólo se basan sobre factores nutricionales, predictibilidad y abundancia del recurso en el ambiente, sino también porque proporcionaron materias primas para la producción de tecnología (Bjerck, Zangrando, Breivik, Piana y Negre, 2016). Como parte de este modelo, también se sostuvo que los grupos humanos encontraban en el mar y en la costa la mayor parte de su alimento, mientras que el ámbito interior no suministraba alternativas de consideración, salvo en el relativamente circunscripto sector donde se obtenían guanacos - único mamífero terrestre de importancia económica en la región(Orquera y Piana, 1999). En este sentido, estos camélidos han sido considerados como complementos que proveían flexibilidad al sistema de subsistencia debido a que su aprovechamiento habría implicado diversas limitaciones: tienen poca grasa, su disponibilidad estaba restringida a determinados ambientes y, por lo tanto, su captura habría sido más "costosa" que la de los pinnípedos (Orquera y Piana, 1999).

No obstante, sea por factores ambientales o demográficos, la capacidad sustentadora de los pinnípedos y la disponibilidad de guanacos en el ambiente no habría sido constante a lo largo de la margen meridional de Tierra del Fuego (Zangrando, 2009; Zangrando, Borrazzo, Tivoli, Alunni y Martinoli, 2013). Esto no sólo se evidencia a partir de las variaciones en la representación taxonómica de los conjuntos arqueofaunísticos fechados a comienzos del Holoceno medio, sino también por cambios en la distribución y abundancia espacial de estos recursos. De este modo, el uso de los guanacos y del espacio terrestre pudo variar conforme a las características del entorno (Raedeke, 1978) y la manera en que se estructuró la oferta espacial de las principales presas para la dieta.

En el marco de esta problemática, el objetivo de este trabajo es evaluar los modos de explotación de guanacos y, en función de esta información, explorar también el rol que pudieron haber tenido los espacios terrestres para la economía de los cazadoresrecolectores y pescadores marinos que habitaron la costa sur de Tierra del Fuego durante el Holoceno medio. Para ello, se discutirán los resultados de los análisis arqueofaunísticos efectuados sobre restos de guanacos provenientes de tres conjuntos con cronologías 

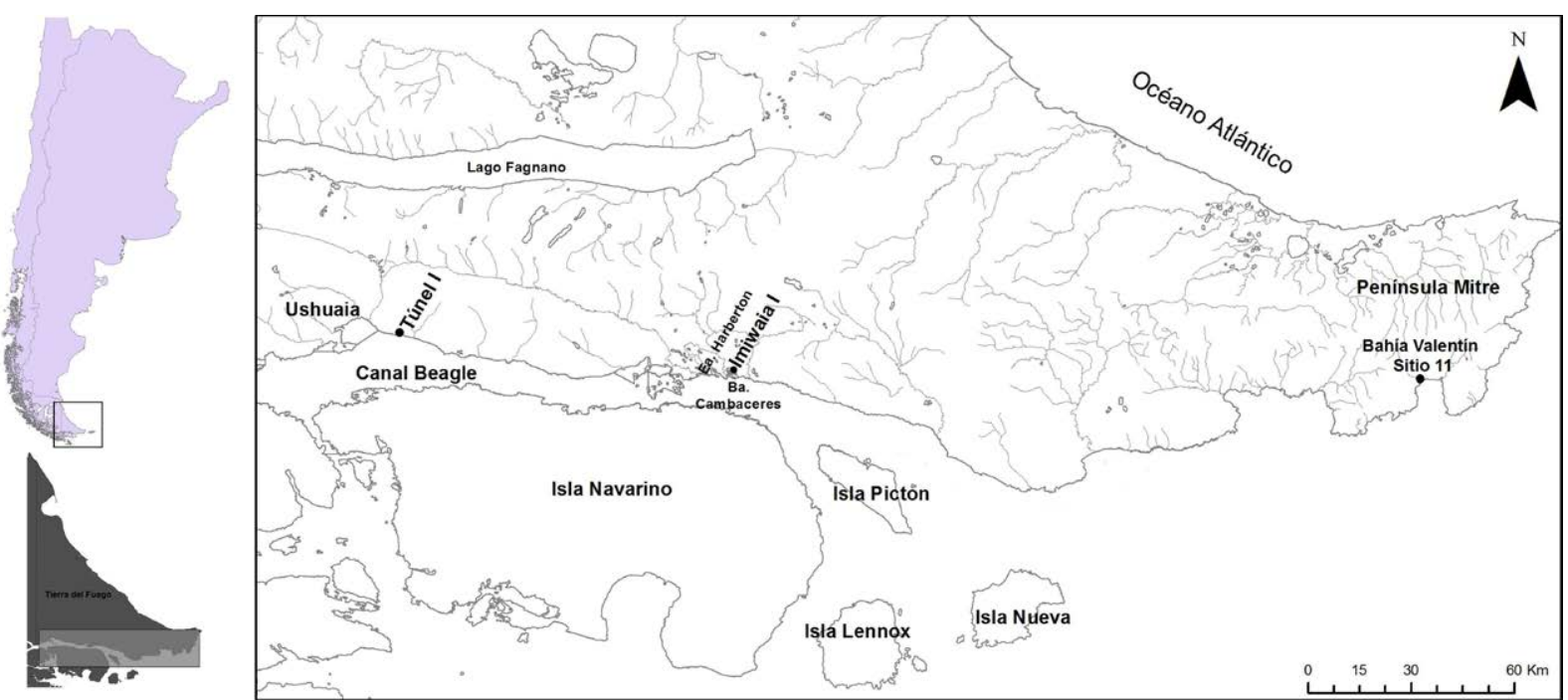

Figura 1. Área de estudio y localización de los sitios analizados en este trabajo.

similares, pero emplazados en entornos ambientales distintos (Figura 1): capa D de Túnel I (6400-4500 años AP), Segundo Componente de Imiwaia I (6000-5700 años AP) y el Bloque Temprano de Bahía Valentín Sitio 11 (5100-4300 años AP).

\section{Contexto ambiental y expectativas}

Uno de los supuestos contemplados en la ocupación inicial de un territorio es que las poblaciones pioneras posean poco conocimiento sobre la estructura espacial y estacional de los recursos allí disponibles (Gamble, 1990; Kelly y Todd, 1988; Zangrando 2009). Ante estas situaciones los grupos humanos tienden a seleccionar los animales de mayor tamaño (Kelly y Todd, 1988), aunque esto no implica que las cacerías centradas en mamíferos grandes ignoren otros recursos (Smith, 1983; Stiner y Munro, 2002; Ugan, 2005). En parte, estas decisiones están fundadas sobre el valor que se le asigna a cada recurso disponible dentro del espacio habitado según una serie graduada de atributos (e.g. peso, rendimiento no alimentario, tamaño de la agregación, densidad, movilidad, contenido de grasas) (Lupo, 2007; Smith, 1983; Stiner y Munro, 2002; Ugan, 2005). Estos, una vez que han sido ordenados en estos términos, pueden clasificarse según su coste de explotación que comprende el tiempo invertido en viajar y buscarlos, además del tiempo de manejo y procesamiento (Lupo, 2007). Es por esto que, en términos espaciales, un aspecto importante de las estrategias de explotación de las presas es el relativo a la estructura y distribución de sus zonas de localización. Esto se debe a que la estructura del medio ambiente y sus componentes afecta a la extensión espacial de las áreas que los grupos humanos recorren en busca de sus recursos (Gamble, 1990) y resulta clave para comprender los aspectos vinculados con el comportamiento de los cazadores-recolectores.

Los guanacos en Tierra del Fuego tienen un peso promedio de 119,7 kg, con valores máximos de hasta $139,8 \mathrm{~kg}$, sin manifestarse diferencias significativas entre ambos sexos (Raedeke, 1978). Sus carnes son magras, pero los huesos de las extremidades poseen tejido medular rico en grasas que se extrae con facilidad. Asimismo, comprenden una fuente importante de materia prima para la producción de tecnología: el cuero es flexible y adecuado para la confección de abrigos, los metapodios son densos y ofrecen resistencia para actividades de presión y fuerza y sus tendones pueden ser usados para 
la costura o confección de armas arrojadizas (Gusinde, 1986; Scheinsohn, 2010). En las costas del canal Beagle la disponibilidad de guanacos no es constante en un ciclo anual dado que en el verano estos camélidos permanecen en sectores elevados y valles interiores de la cordillera (Montes, De Lamo y Zavatti, 2000; Raedeke, 1978). Durante los inviernos las zonas altas se encuentran cubiertas de nieve, situación que impacta sobre el sustrato alimenticio disponible y genera desplazamientos de guanacos hacia las costas en busca de alimento y cobertura térmica. El canal Beagle representa una barrera inferior netamente definida y genera que las tropas se concentren, en gran parte del año, en una estrecha franja litoral. No obstante, las intensidades de estos desplazamientos pueden variar en función de condiciones topográficas y climáticas. En primer lugar hay que considerar que la altura de la cordillera fueguina disminuye en sentido oesteeste. En el tramo occidental del canal Beagle la topografía elevada y el denso bosque pudo haber generado dificultades para que los guanacos y los grupos humanos circulen con facilidad entre la costa y espacios interiores. En su porción oriental, los espacios litorales del canal Beagle (como en los alrededores de Estancia Harberton, ver Figura 1) están comprendidos por campos de drumlins que conforman paisajes de colinas redondeadas que podrían haber funcionado como excelentes "invernadas" de guanacos. La asidua presencia de guanacos en este sector quedó ejemplificada a partir de un evento catastrófico acontecido en la zona de bahía Cambaceres, donde dos manadas enteras de hembras con chulengos se hallaron muertas debido a la acumulación de nieve ocurrida en el invierno de 1995 (Estévez Escalera y Mameli, 2000). Muchos de estos animales estaban al final de su senda, en posición y lugares de descanso y cobijo, rodeados de bosteaderos o en grupos de dos o tres. Otros individuos se hallaron con un patrón más disperso, muertos por desnutrición o accidentados. Es evidente que en inviernos tan rigurosos, la costa del canal Beagle constituye un cul de sac del que no pueden escapar los animales en busca de lugares menos rigurosos (Estévez Escalera y Mameli, 2000). La disponibilidad de guanacos pudo haber sido aún mayor en bahía Moat y Península Mitre, dado que la altura del espaldar montañoso disminuye significativamente y los valles son más amplios y transversales a la costa proporcionando un acceso directo hacia el interior. Asimismo, los espacios boscosos aquí son más abiertos, entre los cuales se desarrollan superficies de turberas, pastizales y juncales que ofrecen valores pastoriles moderadamente altos para el forrajeo de guanacos (Alunni y Zangrando, 2012; Heane, Cavagnaro, Zangrando y Crojetovich, 2011). Incluso se ha propuesto, a diferencia del sector central del canal Beagle, que la disponibilidad de estos camélidos en las costas de Península Mitre habría sido más constante a lo largo del ciclo anual, sin marcados patrones estacionales (Merino y Cajal, 1993). Cabe destacar que estas observaciones sobre la disposición actual de los guanacos habría sido relativamente similar hacia el Holoceno medio, cuando el bosque denso y cerrado de Nothofagus spp. ya se extendía, no sólo a lo largo del canal Beagle, sino también en valles tributarios interiores de los Andes fueguinos del sur de la isla como consecuencia de condiciones frías y húmedas (Heusser, 2003; Borromei et al., 2007). Desde ese entonces no hay registro de alteraciones significativas en el ámbito terrestre que permitan suponer un giro sustancial en las actividades cinegéticas (Fernández et al., en prensa).

En resumidas palabras, la información disponible para la costa sur de Tierra del Fuego indica que la distribución de guanacos no es uniforme y se pueden esperar variaciones en su grado de accesibilidad. Esto pudo haber dado lugar a distintas decisiones logísticas sobre la forma de captura, qué partes transportar al campamento base, cómo procesarlos y prepararlos para el consumo. En este sentido, el rol que cumplió el principal recurso terrestre para poblaciones pioneras requiere ser reevaluado para distintos sectores de la costa meridional de Tierra del Fuego.

En términos de subsistencia, las diferentes decisiones tomadas por los cazadoresrecolectores repercuten de distinto modo en la utilización del espacio y la generación de residuos. Los patrones de almacenamiento, procesamiento, consumo y desecho 
implícitos en los materiales alimenticios reflejan las estrategias adaptativas a condiciones ecológicas variables. Una manera de ilustrar estas pautas de organización de la subsistencia es a través de los clásicos modelos de transporte (Cannon, 2003; Metcalfe y Barlow, 1992; Lupo, 2006, 2007; Orian y Pearson, 1979; entre otros). Esencialmente podrían esperarse dos estrategias si el cazador decide maximizar el volumen del producto animal que ingresará al campamento base y no existen constreñimientos en el transporte (véase Alunni, 2018a): 1) transportar la carcasa completa; o 2) descarnar en el lugar de matanza aquellas unidades anatómicas que requieren menor tiempo de procesamiento y en cuyos huesos queda poca carne adherida (producto remanente, sensu Lupo, 2006) (miembros delanteros y traseros), y transportar respectivamente costillas, vertebras y pelvis. En cambio, si el peso de la carga es una variable importante por considerar, el cazador buscará minimizar el costo de transporte al incrementar el tiempo dedicado en procesar las carcasas en el lugar de matanza en detrimento del producto animal remanente. Los elementos pesados o con bajo contenido de carne y lípidos serían descarnados y descartados en el lugar de matanza/procesamiento. No obstante, si bien estos datos conforman un marco de referencia válido para entender las modalidades de aprovechamiento de guanacos es necesario considerar, además de los volúmenes de carne y lípidos, las necesidades dietarias y el tipo de nutriente que se buscó obtener. Por ejemplo, en el caso hipotético de que un cazador requiera aumentar la ingesta de grasas pero a su vez también reducir el peso de la carga, es probable se descarte costillas y vértebras, resignando con ello el producto remanente que estas porciones contienen, y se priorice el transporte de los miembros al lugar de consumo. Las frecuencias anatómicas y los patrones de procesamiento que resultan de estos comportamientos pueden ser usados como proxis para inferir desplazamientos espaciales en busca de recursos. Por ejemplo, cuanto mayor sea el tiempo de búsqueda y manejo (sensu Bettinger, 1991), más selectivo será el transporte de porciones anatómicas y mayor el descarte de elementos con menor rendimiento y mayores costos de procesamiento. Si se acepta que los factores geográficos y ecológicos disímiles a lo largo de la costa sur de Tierra del Fuego habrían condicionado las pautas de explotación de guanacos en las poblaciones cazadoras-recolectoras, sería factible pensar que las cacerías se organizaron a partir de distintos rangos espaciales de aprovisionamiento. En este sentido, se espera que estos rangos fueran más amplios en el canal Beagle que en sectores más orientales de Península Mitre. Esta diversidad pudo extenderse también sobre diferentes modos de procesar, transportar y consumir guanacos en función de su disponibilidad y la de otros recursos de importancia para la subsistencia de los cazadores-recolectores.

\section{Conjuntos zooarqueológicos}

Las muestras faunísticas discutidas en este trabajo provienen de tres depósitos excavados en diferentes localidades de la costa sur de Tierra del Fuego. El primero de ellos corresponde a los restos de guanacos recuperados de la capa D de Túnel I (ca. 6400 a 4500 años AP), situado en el tramo occidental del canal Beagle (Figura 1). Se trata de un depósito de conchero, del cual se excavaron $150 \mathrm{~m}^{2}$, en donde los pinnípedos (principalmente A. australis) constituyeron el principal recurso explotado y los camélidos tuvieron una importancia significativamente menor (Tabla 1). Esto es coherente con una teóricamente escasa disponibilidad de guanacos en torno al sitio y una mayor dificultad para acceder hacia el interior montañoso y boscoso para su captura (Orquera y Piana, 1999). Vázquez (2015) estudió las pautas de aprovisionamiento de guanacos de este conjunto y observó una mayor frecuencia de miembros y cabeza por sobre la región axial. Este autor asoció el perfil anatómico con una tendencia hacia el transporte diferencial de los miembros, lo que sugiere un patrón de selección tendiente a minimizar costos de transporte. Las estrategias de obtención habrían sido oportunistas y de pequeña escala, destacándose la explotación de tropillas familiares 


\begin{tabular}{|l|c|c|c|c|c|c|}
\hline \multirow{2}{*}{ Taxón } & \multicolumn{2}{|c|}{ Capa D de Túnel I } & \multicolumn{2}{c|}{$\begin{array}{c}\text { Segundo Componente de } \\
\text { Imiwaia I }\end{array}$} & \multicolumn{2}{c|}{$\begin{array}{c}\text { Bloque Temprano de } \\
\text { BVS11 }\end{array}$} \\
\cline { 2 - 7 } & NISP & NISP\% & NISP & NISP\% & NISP & NISP\% \\
\hline Pinnípedos & 80.000 & 63,8 & 3.317 & 17,4 & 409 & 26,0 \\
Guanacos & 5.854 & 4,7 & 3.406 & 17,9 & 533 & 33,8 \\
Aves & 36.057 & 28,8 & 1.964 & 10,3 & 589 & 37,4 \\
Peces & 2.611 & 2,1 & 20.366 & 53,4 & 22 & 1,4 \\
Cetáceos & 858 & 0,7 & 206 & 1,1 & 22 & 1,4 \\
\hline Total & $\mathbf{1 2 5 . 3 8 0}$ & - & $\mathbf{1 9 . 0 8 0}$ & - & 1.575 & - \\
\hline
\end{tabular}

Tabla 1. NISP de los restos óseos provenientes de los sitios analizados: Capa D de Túnel I (Orquera y Piana 1999; Vázquez 2015), Segundo Componente de Imiwaia I (Orquera y Piana 1999; Zangrando 2009; Alunni 2016; Zangrando et al. 2016); Bloque temprano de BVS11 (Zangrando et al. 2009; Alunni 2018; Martinoli 2018).

y algunos episodios de caza en el lapso verano-otoño. Asimismo, planteó que todas las porciones que arribaron al sitio fueron faenadas y procesadas en forma completa $\mathrm{e}$ intensiva, situación que se manifiesta por las numerosas marcas antrópicas y el consumo de todas las fuentes de médula ósea disponibles. No obstante, destacó la incidencia de procesos atricionales, particularmente la acción de los carnívoros.

El segundo conjunto proviene del sitio Imiwaia I, en el interior de la bahía Cambaceres, sector oriental del canal Beagle (Orquera y Piana, 2000). El material analizado proviene de una excavación de $50 \mathrm{~m}^{2}$ e incluye los restos de camélidos provenientes del Segundo Componente (capas K, L y M) (Alunni, 2016), el cual cubre una cronología que va de los ca. 5900 a 5700 años AP. Este depósito consiste en un conchero en el cual se registró un incremento en la abundancia relativa de guanacos con relación a la capa $\mathrm{D}$ de Túnel I (Tabla 1), aunque el aporte dietario de los pinnípedos continuó siendo mayor (Martinoli, 2015; Orquera y Piana, 1999; Zangrando, 2009). Es probable que la localización del sitio haya favorecido el encuentro entre humanos y guanacos y el concomitante aumento en la representación de camélidos.

Finalmente, el Bloque Temprano de Bahía Valentín Sitio 11 (BVS11) abarca las capas X, T, S, R, Q, P y O y cubre un lapso que va desde los ca. 5080 a 4300 años AP (Vázquez, Zangrando, Tessone, Ceraso y Sosa, 2007; Zangrando, Tessone y Vázquez, 2009). Se excavaron $2 \mathrm{~m}^{2}$ y los depósitos estratigráficos están compuestos fundamentalmente por sedimento arenoso y lentes carbonosas. El Bloque Temprano de BVS11 conjunto señala una disminución en el consumo de pinnípedos y un incremento en la abundancia relativa de guanacos (Tabla 1). Los estudios exhaustivos sobre los perfiles de mortalidad, las medidas de abundancia anatómica y las pautas de procesamiento son presentados en esta oportunidad y comparados con los resultados provenientes de los conjuntos más tempranos del canal Beagle.

\section{Métodos}

Se utilizaron diferentes medidas convencionales para evaluar la diversidad y abundancia relativa de individuos y unidades anatómicas (e.g. Binford, 1978; Klein y Cruz-Uribe, 1984; Lyman, 1994). Estas incluyen el Número de Especímenes Identificados (NISP), los cuales fueron clasificados según su correspondencia anatómica y clases de edad. A partir de estos cálculos se determinó el Número Mínimo de Individuos (NMI) y los cálculos de abundancia anatómica (NME, MAU, MAU\% e Índice de Supervivencia). La determinación etaria se realizó a partir del cronograma de erupción, desarrollo 
y desgaste dentario y del grado de fusión ósea (De Lamo, 1990; Kaufmann, 2009; L'Heureux y Kaufmann, 2012; Oporto, Bigatti y Larrieu, 1979; Puig y Monge, 1983; Raedeke, 1978).

El estado de la muestra fue contemplado por medio de diferentes criterios. Por un lado, se consideraron los valores de Densidad Mineral Ósea (DMO) publicados por Elkin (1995), los cuales fueron correlacionados con el MAU\% de los extremos proximales y distales de los huesos largos (húmero, radio-ulna, fémur y tibia), excluyendo los valores calculados para las diáfisis (Vázquez, 2015). Luego, se utilizaron los estadios de meteorización propuestos por Behrensmeyer (1978). Finalmente, se analizó la incidencia de los carnívoros sobre la representatividad de la muestra, ya que estos pueden tener acceso a los restos óseos descartados luego de las actividades de procesamiento y consumo humano. En la actualidad, en Tierra del Fuego el único carnívoro autóctono presente es el zorro colorado, el cual llega a alcanzar $55 \mathrm{~cm}$ de altura y un peso corporal de $11 \mathrm{~kg}$. Este animal carroña animales muertos, como ungulados y carcasas de animales marinos que se acumulan en las playas, aunque también puede capturar presas pequeñas como aves, roedores e insectos. Estas acciones dejan marcas que pueden ser distinguidas de las de origen antrópico porque tienen morfologías características (véase Binford, 1981; Borrero, 1990; Martin, 1998; Shipman, 1981).

La representación de partes esqueletarias fue evaluada según el Îndice de Supervivencia y siguiendo la propuesta de dividir la carcasa por regiones anatómicas según los productos que proporcionan (De Nigris, 2004; Stiner, 1994). Asimismo, fueron utilizados tres índices de rendimiento económico (Kcal/g, Kcal/h, MUI) que consideran, además de los valores de anatomía económica (Borrero, 1990; De Nigris y Mengoni Goñalons, 2004; Mengoni Goñalons, 1996), el peso de cada elemento y el tiempo que conlleva procesarlos (véase Alunni, 2018a para una discusión y reconstrucción de estos índices). Esto permite no sólo considerar el volumen ( $\mathrm{g}$ ) y tipo de alimento que ingresa al sitio, sino también el peso implicado en el transporte y el tiempo que requiere procesar cada elemento, bajo el supuesto de que el valor de cada parte esqueletaria puede modificarse si al volumen de carne y médula se le agregan estos procesos (Alunni, 2018a). Para ello, se correlacionaron estos índices con el MAU\% y se empleó el coeficiente de correlación por rango de rho Spearman con un p-valor de 0,01. Asimismo, estos cálculos fueron realizados siguiendo la propuesta de Marean y Cleghorn (2003; ver también Faith y Gordon, 2007) sobre utilizar aquellos elementos que tienen menores posibilidades de desaparecer o permanecer como no identificables antes de pasar a formar parte del registro arqueológico. Los autores enmarcan a estos huesos dentro del set de alto potencial de supervivencia, y engloban las porciones que normalmente son evitadas por los carnívoros porque poseen tejido cortical que resiste a la fractura. $\mathrm{Al}$ aplicar este modelo al análisis de restos óseos de guanaco en Tierra del Fuego, es preciso considerar que aquí no existen grandes carnívoros capaces de generar intensos daños sobre las osamentas (Borrero, 1990). Es por este motivo que resulta necesario adecuar el modelo de Marean y Cleghorn (2003) según el potencial destructivo de los zorros colorados. Las observaciones actualísticas efectuadas sobre esta especie indican que los zorros no tienen la capacidad de ingerir falanges enteras, aunque sí de modificar mecánicamente las porciones con contenido trabecular y grasa ósea (Borrero, 1990, 2007; Estévez Escalera y Mameli, 2000). Por ello, se propone que para este caso de estudio el set de alto potencial de supervivencia para guanacos en Tierra del Fuego debería estar compuesto por: cráneo (dientes, petroso), mandíbula, huesos largos, astrágalo y falanges 1 .

Por último, se analizaron las marcas de procesamiento, tales como las de corte, impacto, machacado y raspado (Binford, 1981; Lyman, 1987; Soulier y Costamagno, 2017, entre otros). La determinación de las modificaciones sobre las superficies óseas fue efectuada a ojo desnudo y con bajos aumentos, utilizando una lupa binocular de entre 6X y 50X. Se registró la ubicación, frecuencia y la orientación de estas huellas, considerando que 
dichas características pueden estar relacionadas con actividades específicas, como por ejemplo el cuereo, la extracción de tendones, el desmembramiento o el descarne. También se midió la fragmentación a través de la relación NISP/NME, la proporción de elementos completos y la forma y textura del borde de fractura (Johnson, 1985; Lyman, 1994; Morlan, 1984).

\section{Resultados}

El NISP de restos de guanacos identificados a nivel anatómico en la capa D de Túnel I es de 5.854 de los cuales se determinaron 23 individuos (Tabla 2). Por su parte, en el Segundo Componente de Imiwaia I se cuantificó un NISP de 3.404 y un NMI de 14 camélidos, mientras en el Bloque Temprano de BVS11 los especímenes suman un total de 533 y un NMI de cinco.

\section{Estado de la muestra}

En primer lugar, se evaluaron los efectos de la Densidad Mineral Ósea sobre la representatividad anatómica. Las correlaciones entre los índices de DMO y la frecuencia de articulaciones proximales y distales muestran resultados positivos y muy significativos para la capa D de Túnel I, lo que sugiere que los elementos con mayor densidad mineral estarían mejor representados (Tabla 3). Una situación similar podría ser planteada para el Segundo Componente de Imiwaia I, donde el resultado fue positivamente alto aunque no significativo al considerar un p-valor de 0,04. En cambio, en el Bloque Temprano de BVS11 la acción de procesos atricionales parece no haber afectado de manera determinante la supervivencia de los especímenes con menor densidad estructural.

El registro de la meteorización mostró la existencia de un patrón similar en los tres conjuntos, caracterizado por una preponderancia de especímenes en estadios bajos. Los estadios medios, en cambio, son poco frecuentes, mientras los más altos sólo se identificaron en unos pocos huesos provenientes de Imiwaia I y BVS11 (Figura 2). Esta información permite suponer un período de exposición no muy largo y un enterramiento relativamente homogéneo de los conjuntos arqueofaunísticos. Esta interpretación podría respaldarse si consideramos la alta tasa de acumulación de valvas que normalmente caracteriza a la formación de concheros. Por un lado, la capa D de Túnel I y los estratos que componen el Segundo Componente de Imiwaia I están constituidos por acumulaciones de moluscos, cuyo descarte produce elevados volúmenes de desperdicio y alcanzan una alta tasa de sedimentación (Orquera y Piana, 2000). Esto origina un rápido crecimiento y acumulación de los conchales, que a su turno ayuda a proteger los materiales arqueológicos contra el deterioro por acción de procesos atmosféricos. Si bien el Bloque Temprano de BVS11 carece de estructuras de concheros en sentido estricto del término, en la base una de sus capas (la capa X) se halló una lente muy extensa de periostraco de mitílidos grandes (Zangrando, Tessone y Vázquez, 2009). Esto permitió a los autores documentar el consumo de moluscos, por lo que podríamos presumir que similares situaciones de descarte habrían tenido lugar en ciertos momentos de la ocupación, aunque la tasa de acumulación de valvas pudo haber sido menor.

Con respecto a los carnívoros, es evidente que su actividad carroñera influyó sobre la representatividad anatómica de los conjuntos, aunque resulta difícil estimar el alcance de dicho accionar. Sus huellas se registran en porcentajes más altos en Túnel I ( $\mathrm{n}=175$; $\mathrm{n} \%=5,08 \%)$, mientras que en Imiwaia I la acción de carnívoros fue identificada en 14 especímenes $(0,4 \%)$, y en BVS11 solo se halló en un fragmento óseo (epífisis de fémur distal). En general, las marcas son de perforaciones ubicadas en las costillas, las apófisis de vértebras, en la pelvis, en las epífisis de los huesos largos y en los autopodios. En 


\begin{tabular}{|c|c|c|c|c|c|c|c|c|c|c|c|c|c|c|c|}
\hline \multirow[b]{2}{*}{ Unidades anatómicas } & \multicolumn{5}{|c|}{ Capa D de Túnel I } & \multicolumn{5}{|c|}{ Segundo Componente de Imiwaia I } & \multicolumn{5}{|c|}{ Bloque Temprano de BVS11 } \\
\hline & $\frac{\hat{\aleph}}{z}$ & $\sum_{\mathbf{Z}}^{\mathrm{W}}$ & $\sum$ & $\stackrel{2}{\Sigma}$ & $\stackrel{\stackrel{0}{2}}{\Sigma}$ & $\frac{\bar{\aleph}}{z}$ & $\sum_{Z}$ & $\sum_{\mathbf{Z}}$ & $\underset{\Sigma}{2}$ & $\stackrel{\circ}{\stackrel{\circ}{\Sigma}}$ & $\frac{\hat{n}}{z}$ & $\sum_{\mathbf{Z}}^{山}$ & $\sum_{\mathbf{Z}}$ & $\stackrel{?}{\Sigma}$ & $\stackrel{\stackrel{\circ}{2}}{\stackrel{1}{\Sigma}}$ \\
\hline Cráneos & 171 & 10 & 10 & 10 & 48 & 30 & 3 & 3 & 3 & 28 & 10 & 1 & 1 & 1 & 40 \\
\hline Mandíbulas & 130 & 18 & 18 & 18 & 86 & 18 & 3 & 3 & 3 & 28 & 5 & 2 & 2 & 2 & 80 \\
\hline Axis & 18 & 11 & 11 & 11 & 52 & 4 & 2 & 2 & 2 & 19 & o & o & $\mathrm{o}$ & o & o \\
\hline Atlas & 17 & 11 & 11 & 11 & 52 & 3 & 2 & 2 & 2 & 19 & o & o & 0 & 0 & o \\
\hline Vértebras cervicales & 193 & 50 & 10 & 10 & 48 & 36 & 16 & 4 & 3,2 & 30 & 13 & 6 & 1 & 1,2 & 48 \\
\hline V. torácicas & 150 & 69 & 6 & 6 & 27 & 65 & 23 & 4 & 1,9 & 18 & 14 & 8 & 2 & 0,7 & 26,7 \\
\hline V. lumbares & 237 & 57 & 8 & 8 & 39 & 196 & 24 & 4 & 3,4 & 32 & 14 & 7 & 2 & 1 & 40 \\
\hline V. caudales & 27 & - & - & - & - & 15 & 16 & 4 & 2,3 & 22 & o & o & 0 & o & o \\
\hline V. sacras & 21 & - & - & - & - & 3 & 1 & - & - & - & o & o & 0 & o & $\mathrm{o}$ \\
\hline Costillas & 451 & 142 & 6 & 6 & 28 & 132 & 52 & 4 & 2,2 & 21 & 43 & 21 & 3 & 0,9 & 35 \\
\hline Escápulas & 92 & 24 & 14 & 12 & 57 & 15 & 7 & 5 & 3,5 & 33 & 4 & 2 & 2 & 1 & 40 \\
\hline Pelvis & 143 & 14 & 14 & 14 & 67 & 34 & 6 & 6 & 6 & 56 & 1 & 1 & 1 & 1 & 40 \\
\hline Húmeros & 193 & 32 & 16 & 16 & 76 & 68 & 15 & 10 & 7,5 & 70 & 11 & 3 & 2 & 1,5 & 60 \\
\hline Radio-ulnas & 311 & 42 & 23 & 21 & 100 & 82 & 17 & 11 & 8,5 & 80 & 9 & 4 & 2 & 2 & 80 \\
\hline Fémures & 198 & 17 & 17 & 16 & 74 & 115 & 18 & 14 & 9 & 84 & 19 & 5 & 3 & 2,5 & 100 \\
\hline Tibias & 211 & 33 & 19 & 17 & 79 & 87 & 19 & 10 & 9,5 & 89 & 10 & 4 & 3 & 2 & 80 \\
\hline Metapodios & 317 & 50 & 13 & 13 & 60 & 130 & 22 & 6 & 5,5 & 52 & 23 & 7 & 3 & 1,8 & 70 \\
\hline Metatarsos & 58 & 31 & 16 & 16 & 74 & 14 & 9 & 7 & 4,5 & 42 & 1 & 1 & 1 & 0,5 & 20 \\
\hline Metacarpos & 56 & 22 & 11 & 11 & 53 & 10 & 6 & 3 & 3 & 28 & o & o & 0 & o & o \\
\hline Sesamoideos & 21 & - & - & - & - & 17 & 17 & - & - & - & 12 & 3 & 1 & - & - \\
\hline Rótulas & 10 & 17 & 9 & 9 & 41 & 13 & 9 & 5 & 4,5 & 42 & o & o & 0 & 0 & o \\
\hline Falanges 1 & 279 & 107 & 14 & 13 & 64 & 150 & 65 & 9 & 8,1 & 76 & 18 & 11 & 2 & 1,4 & 55,2 \\
\hline Falanges 2 & 146 & 75 & 10 & 9 & 45 & 92 & 53 & 7 & 6,6 & 62 & 7 & 6 & 1 & 0,8 & 30 \\
\hline Falanges 3 & 51 & 49 & 7 & 6 & 29 & 31 & 30 & 4 & 3,8 & 35 & 3 & 3 & 1 & 0,4 & 15,2 \\
\hline Carpianos & 134 & 134 & 12 & 13 & 60 & 67 & 66 & 9 & 8,3 & 77 & 2 & 2 & 1 & 0,3 & 11,4 \\
\hline Tarsianos & 91 & 91 & 15 & 12 & 57 & 65 & 64 & 12 & 11 & 100 & 5 & 5 & 2 & 1 & 40 \\
\hline Astrágalos & 29 & 26 & 15 & 13 & 62 & 23 & 15 & 8 & 7,5 & 70 & 2 & 2 & 2 & 1 & 40 \\
\hline Calcáneos & 79 & 36 & 18 & 18 & 86 & 34 & 15 & 10 & 7,5 & 70 & 3 & 2 & 2 & 1 & 40 \\
\hline Total parcial & 3.834 & 1.168 & 23 & - & - & 1.549 & 595 & 14 & - & - & 229 & 106 & 5 & - & - \\
\hline
\end{tabular}

Tabla 2. Medidas de abundancia calculadas para los restos de guanacos de los tres conjuntos analizados.

\begin{tabular}{|l|c|c|}
\hline Conjuntos zooarqueológicos & $r_{s}$ & p-valor \\
\hline Capa D de Túnel I & $r_{s}=0,77$ & $p$-valor $=0,001$ \\
Segundo Componente de Imiwaia I & $r_{s}=0,73$ & $p$-valor $=0,04$ \\
Bloque Temprano de BVS11 & $r_{s}=0,16$ & $p$-valor $=0,7$ \\
\hline
\end{tabular}

Tabla 3. Correlaciones entre el MAU\% y los índices de Densidad Mineral Ósea.

Imiwaia I y Túnel I la presencia de algunas de estas huellas sobre las caras articulares de los huesos largos permite inferir que los cánidos tuvieron acceso a las carcasas luego del descarte de los miembros desarticulados. 


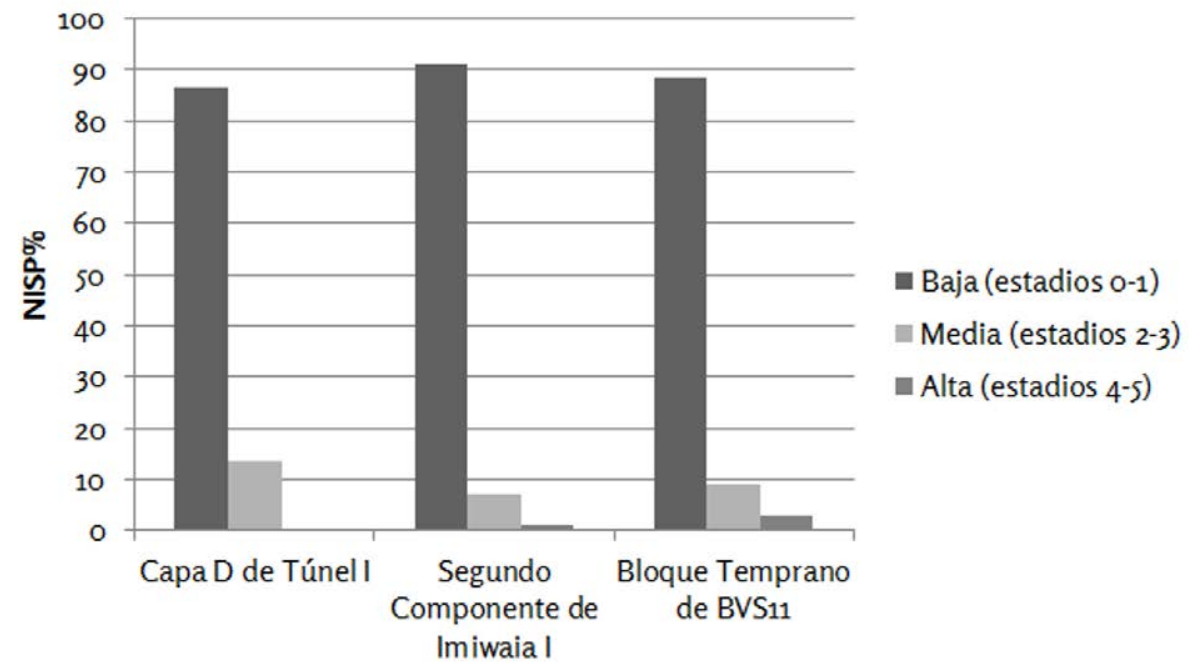

Figura 2. Estadios de meteorización para los restos óseos de guanacos de los conjuntos analizados.

\section{Edady sexo}

Los perfiles de mortalidad identificados según el grado de fusión ósea y el cronograma de desarrollo/desgaste dental muestran diferencias entre los dos conjuntos del canal Beagle por un lado y el Bloque Temprano de BVS11 por otro (Figura 3). Los primeros señalan una mayoritaria presencia de individuos adultos en edad reproductiva, aunque también se registraron crías que permiten suponer cacerías de tropillas familiares. El Bloque Temprano de BVS11, por su parte, exhibe las mismas clases de edad, pero con un leve aumento en la proporción de chulengos y una disminución de los adultos capturados. El sexo no pudo ser definido para ningún conjunto.

\section{Transporte}

Con respecto a las medidas de abundancia anatómica, en los tres conjuntos se observa que todos los elementos del esqueleto de un guanaco se encuentran presentes, pero con frecuencias variables. Las muestras del canal Beagle exhiben porcentajes de huesos apendiculares que rondan el 70\%, mientras que los axiales no superan el $35 \%$. En el Bloque Temprano de BVS11, si bien los miembros continúan siendo más frecuentes, la diferencia entre ambas zonas del esqueleto no es tan marcada: la región axial representa aproximadamente el $43 \%$ de la muestra, en tanto la apendicular el $57 \%$.

La relación por regiones anatómicas de acuerdo al producto primario que proporcionan permite precisar mejor estas similitudes y diferencias (Figura 4). La tendencia general de los tres conjuntos se caracteriza por la preponderancia de los huesos que proveen sólo médula (extremidades inferiores, falanges y calcáneos) y de aquellos que brindan carne y médula (extremidades medias y superiores; e. g., radio-ulnas y tibias, fémures). No obstante, si se comparan en detalle las regiones anatómicas más representadas para cada sitio, se nota la existencia de cierta variabilidad: el Índice de Supervivencia de Túnel I muestra un perfil anatómico más completo que el que exhibe BVS11 y, principalmente, Imiwaia I (ver Figura 4). Este último depósito además presenta la mayor desigualdad entre el número de elementos axiales y apendiculares.

Con respecto a las correlaciones entre las medidas de abundancia anatómica y los valores de rendimiento económico, se destaca que en Imiwaia I la relación entre 


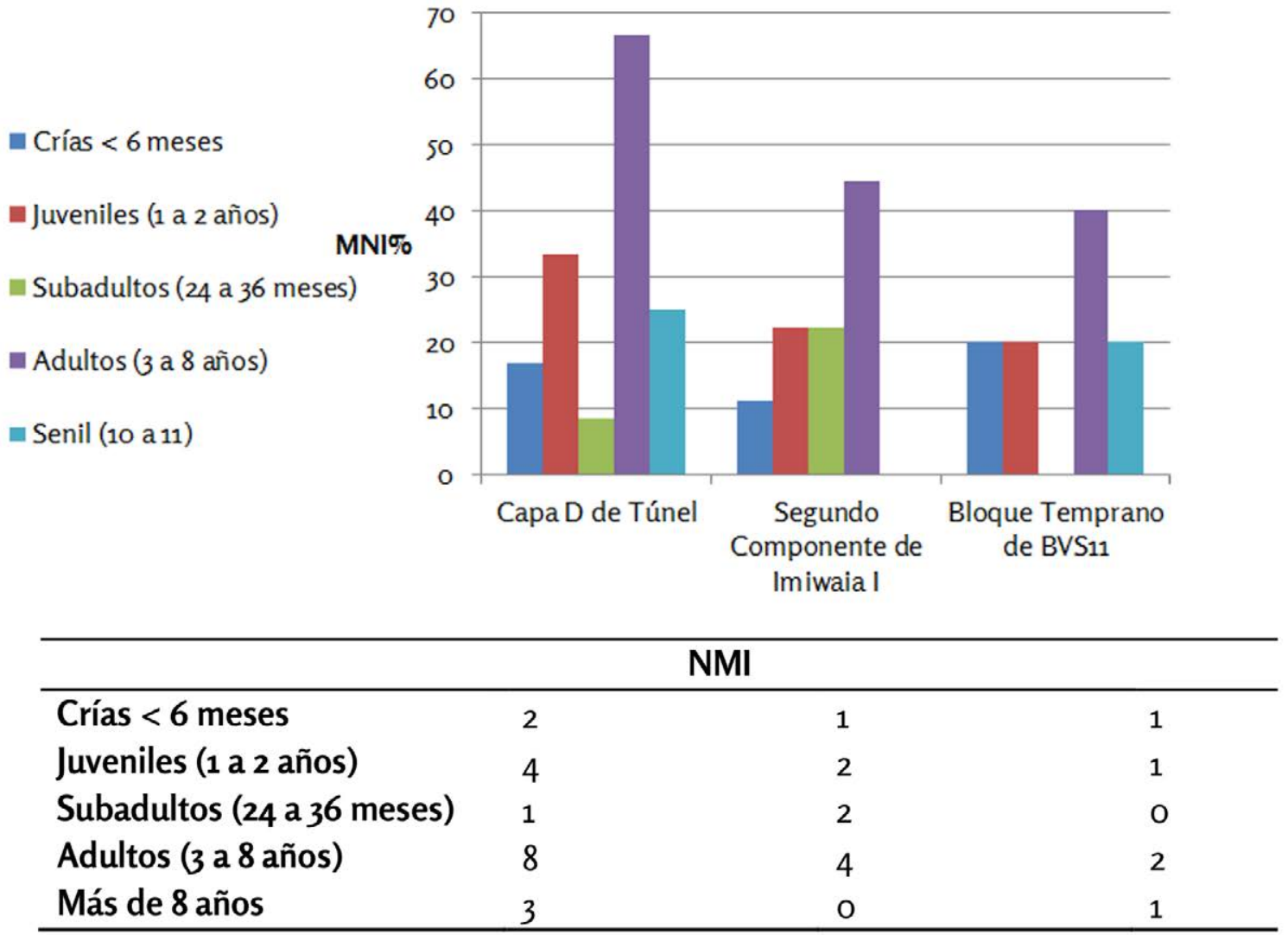

Figura 3. Determinación de los perfiles de edad de los tres sitios analizados.

el MAU\% con las Kcal/h y el MUI resultó ser negativa, fuerte y estadísticamente significativa (Tabla 4), lo que sugeriría el ingreso al sitio de porciones con bajo retorno en función del tiempo que conlleva procesar cada unidad y el valor en carne que posean los elementos. En otras palabras, el patrón que se observa es una baja frecuencia de huesos ricos en carne y que demandan mucho tiempo de procesamiento, como las vértebras y el costillar. En cambio, las correlaciones entre las $\mathrm{Kcal} / \mathrm{g}$ y el MAU\% en Imiwaia I arrojaron resultados débiles y no significativos (Tabla 4). Esta situación no permite vincular el ingreso de elementos según el rendimiento energético de cada parte relativo con el peso que implica transportarlos a la localidad de consumo final. En Túnel I y en BVS11, por el contrario, las correlaciones entre los índices y el MAU\% fueron débiles y no significativas (Tabla 4), situación que sugiere el ingreso de porciones sin contemplar el beneficio económico que ofrece cada unidad. Por último, las covarianzas débiles y no significativas entre el MAU\% y el Îndice de Médula (g) invitan a pensar que en todos los casos aconteció el acarreo de todas las porciones que poseen esta sustancia.

Finalmente, si se considera únicamente el set de alto potencial de supervivencia (Tabla 4) observamos que se mantienen resultados similares en tanto prevalecen las correlaciones débiles en BVS11 y las tendencias negativas en Túnel I e Imiwaia I, aunque estas se atenúan y pierden significatividad estadística. Dicha variación alerta sobre la posibilidad de que los procesos destructivos y nutritivos (Marean y Cleghorn, 2003) asociados a la acción de los carnívoros pudieran haber afectado los perfiles anatómicos observados. En este sentido, la menor frecuencia de elementos con bajo potencial de preservación podría estar asociada a este proceso (Vázquez, 2015). 


\section{Segundo Componente de Túnel I}

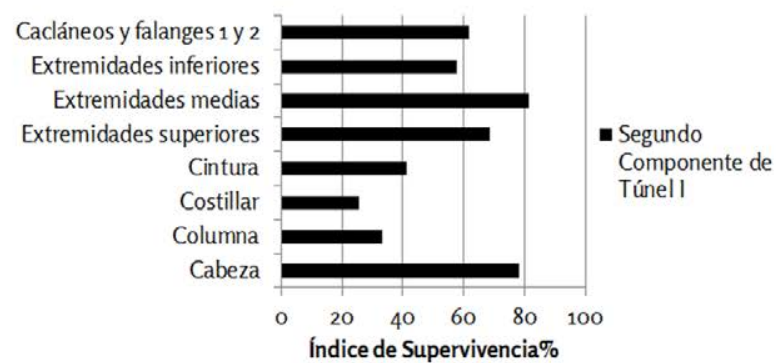

Segundo Componente de Imiwaia I

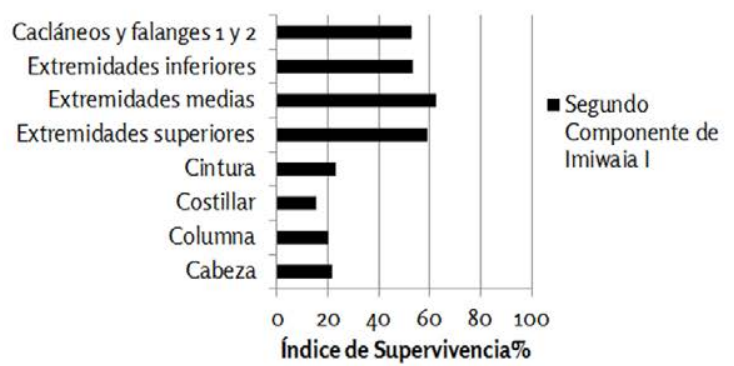

Bloque Temprano de BVS11

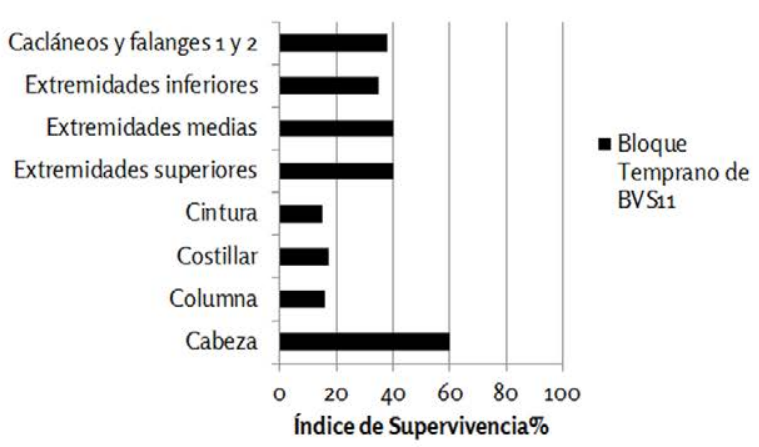

Figura 4. Índice de Supervivencia por regiones anatómicas de acuerdo al producto primario que proporncionan.

\begin{tabular}{|c|c|c|c|c|c|c|}
\hline \multicolumn{7}{|c|}{ Muestra total } \\
\hline & \multicolumn{2}{|c|}{ Capa D de Túnel I } & \multicolumn{2}{|c|}{ Segundo Componente de Imiwaia I } & \multicolumn{2}{|c|}{ Bloque Temprano de BVS11 } \\
\hline & $r_{s}$ & p-valor & $r_{s}$ & p-valor & $r_{s}$ & p-valor \\
\hline $\mathrm{Kcal} / \mathrm{g}$ & $r_{s}=-0,24$ & $\mathrm{p}$-valor $=0,38$ & $r_{s}=-0,3$ & $\mathrm{p}$-valor $=0,2$ & $r_{s}=0,3$ & $\mathrm{p}$-valor $=0,9$ \\
\hline $\mathrm{Kcal} / \mathrm{h}$ & $r_{s}=-0,24$ & $\mathrm{p}$-valor $=0,04$ & $r_{s}=-0,6$ & $p$-valor $=0,01$ & $r_{s}=-0,09$ & p-valor $=0,76$ \\
\hline MUI & $r_{s}=-0,5$ & $\mathrm{p}$-valor $=0,07$ & $r_{s}=-0,6$ & $p$-valor $=0,01$ & $r_{s}=-0,09$ & $p$-valor $=0,2$ \\
\hline Índice de Médula & $r_{s}=0,15$ & $\mathrm{p}$-valor $=0,7$ & $r_{s}=0,4$ & $\mathrm{p}$-valor $=0,4$ & $r_{s}=0,5$ & $p$-valor $=0,2$ \\
\hline \multicolumn{7}{|c|}{ Set de alto potencial de supervivencia } \\
\hline & \multicolumn{2}{|c|}{ Capa D de Túnel I } & \multicolumn{2}{|c|}{ Segundo Componente de Imiwaia I } & \multicolumn{2}{|c|}{ Bloque Temprano de BVS11 } \\
\hline & $r_{s}$ & p-valor & $r_{s}$ & p-valor & $r_{s}$ & p-valor \\
\hline $\mathrm{Kcal} / \mathrm{g}$ & $r_{s}=0,06$ & $p$-valor $=0,86$ & $r_{s}=-0,3$ & $\mathrm{p}$-valor $=0,4$ & $r_{s}=0,41$ & $p$-valor $=0,23$ \\
\hline $\mathrm{Kcal} / \mathrm{h}$ & $r_{s}=0,2$ & $\mathrm{p}$-valor $=0,49$ & $r_{s}=-0,5$ & $\mathrm{p}$-valor $=0,3$ & $r_{s}=-0,35$ & p-valor $=0,36$ \\
\hline MUI & $r_{s}=0,2$ & $\mathrm{p}$-valor $=0,6$ & $r_{s}=-0,2$ & p-valor $=0,7$ & $r_{s}=0,58$ & $\mathrm{p}$-valor $=0,14$ \\
\hline
\end{tabular}

Tabla 4. Correlaciones entre el MAU\% y los índices de rendimiento calculados para los restos de guanacos provenientes de los sitios analizados.

\section{Procesamiento}

Varias son las evidencias que permiten dar cuenta que los conjuntos analizados provienen de sitios en los cuales se llevó a cabo el consumo final de las presas. Los depósitos están compuestos por una gran diversidad de partes esqueletarias y el número de especímenes con huellas es siempre elevado con valores que van del 20\% al 30\% 
del NISP total, datos que son compatibles con la mayor disponibilidad de tiempo y tecnología que se tiene para el procesamiento de los recursos en los sitios ubicados hacia el fin de la secuencia de reducción de una carcasa (Bunn, Bartram y Kroll, 1988; Gifford-Gonzalez, 1989). Las marcas se ubican tanto en la región apendicular como axial sobre sectores de inserciones musculares, extremos articulares y diáfisis (Figura 5).

En los tres conjuntos se identificaron huellas asociadas posiblemente a la remoción del cuero, inferido por la presencia de marcas transversales y profundas sobre segmentos distales de metapodios y en las primeras y segundas falanges. En el Segundo Componente de Imiwaia I también se reconocieron cortes longitudinales en cuneiformes, lunares, accesorios y naviculares que pueden vincularse con esta actividad (Soulier y Costamagno, 2017). Por su parte, en la sección incisiva del cuerpo de una mandíbula proveniente del Bloque Temprano de BVS11 se registraron cortes similares a los que Binford (1981) relaciona con el cuereo (m-1). Finalmente, en algunos especímenes de Túnel I, Imiwaia I y BVS11 existen ciertas marcas cortas, transversales y oblicuas en la parte posterior de los metapodios y en la cara externa de las primeras falanges que podrían asociarse a la remoción de tendones.

Sobre el esqueleto axial se hallaron tanto marcas de corte como de percusión en todos los sitios correspondientes a la extracción de los productos primarios que brinda esta región y a actividades de desarticulación (Figura 5). La separación de los cuerpos vertebrales entre sí quedó evidenciada por cortes sobre las superficies articulares de estos elementos y por cortes transversales sobre las apófisis. Asimismo se registró la disociación de las vértebras y las costillas por incisiones localizadas en las articulaciones proximales de éstas y por marcas en las fóveas costales de las vértebras torácicas. En los tres sitios se han observado también negativos de impacto sobre los procesos transversos y espinosos, que pueden igualmente vincularse a las actividades de desmembramiento y separación de la columna vertebral. El descarne se infiere por cortes longitudinales y transversales sobre las apófisis espinosas y transversas. Se identificaron huellas semejantes a las TV-2 (Binford, 1981), relacionadas con la remoción del músculo durante el trozamiento primario de las vértebras torácicas, y huellas similares en las apófisis espinosas lumbares. En las caras ventrales de algunos cuerpos vertebrales provenientes de Imiwaia I también se observaron cortes que suelen ser el resultado de la evisceración (Binford, 1981). En todos los conjuntos, el descarne de las costillas dejó marcas a lo largo de las caras laterales (RS-1, según Binford, 1981, p. 137).

Los negativos de impacto en las vértebras torácicas podrían estar vinculados con la segmentación de esa parte del espinazo en porciones más chicas, quizá unidades de reparto o consumo final. En las vértebras lumbares, los daños se emplazan mayormente en los procesos transversos, en los sectores cercanos al cuerpo vertebral, lo que podría ser compatible con un seccionamiento tendiente a facilitar el acceso a la médula espinal.

En cuanto al esqueleto apendicular, todos los conjuntos exhiben marcas de corte e impacto (Figura 5), y sugieren la ejecución de las distintas etapas de desorganización de los miembros. Muchas marcas asociadas directamente con zonas articulares se relacionan con acciones de desarticulación, mientras que en las diáfisis de los huesos largos se observaron marcas longitudinales, transversales u oblicuas vinculadas al descarne. En Imiwaia I y Túnel I el desarrollo de esta práctica también se identificó en las pelvis por medio de cortes en la cara lateral del pubis (PS-6, Binford, 1981) y en las escápulas por huellas longitudinales a lo largo del sector medial de la hoja. Con la excepción de unas pocas segundas falanges y del total de terceras, todos los elementos que contienen canal medular presentan algún tipo de fractura, hecho que produjo una escasa frecuencia de elementos enteros (Tabla 5). El alto índice de fragmentación para las porciones superiores, medias e inferiores de los miembros, en conjunto con la ausencia de elementos completos (Tabla 5), muestra una intensa segmentación de estos 

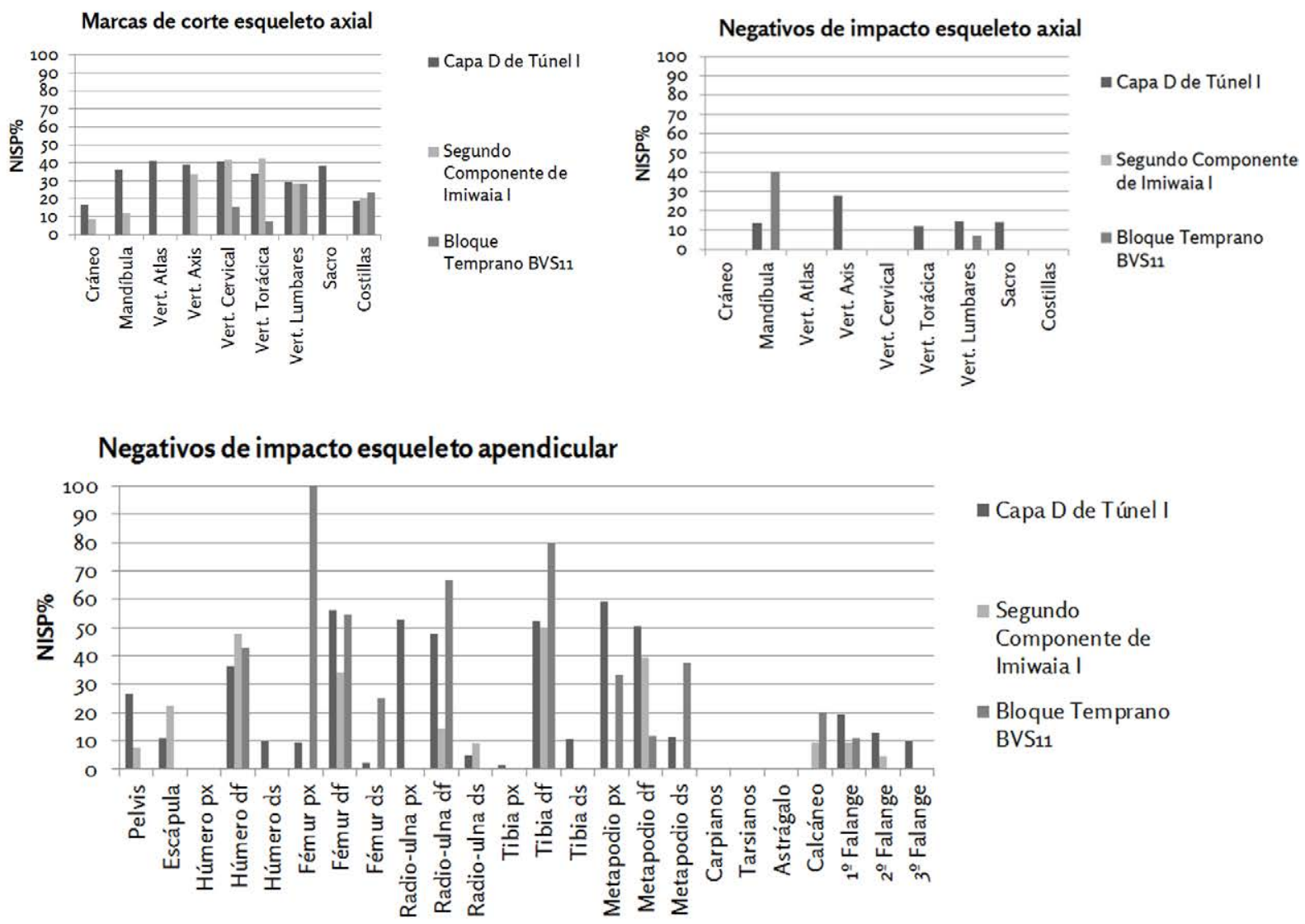

Marcas de corte esqueleto apendicular

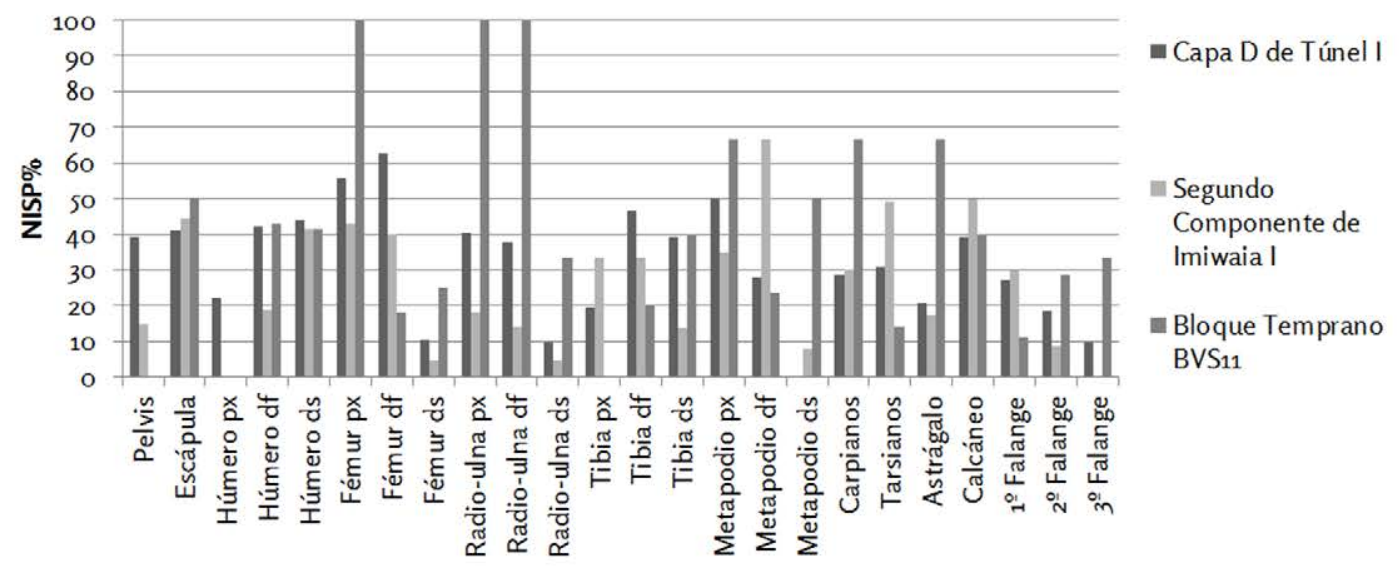

Figura 5. Abundancia de marcas de corte e impacto distribuidas según las distintas porciones anatómicas que componen la carcasa de un guanaco.

elementos que poseen mayores volúmenes de médula. En cambio, el índice NISP/MNE en falanges es menor (Tabla 5), dado que el impacto del golpe tiende a segmentar estos huesos en dos mitades fácilmente reconocibles. La mayoría de los especímenes, sobre todo las diáfisis mediales de los huesos largos, tienen formas de fractura helicoidal y bordes que indican el procesamiento de los elementos en estado fresco. Esto permitiría 


\begin{tabular}{|c|c|c|c|c|c|c|c|c|c|}
\hline \multirow{2}{*}{$\begin{array}{l}\text { Unidades } \\
\text { anatómicas }\end{array}$} & \multicolumn{3}{|c|}{ Capa D de Túnel I } & \multicolumn{3}{|c|}{ Segundo Componente de Túnel I } & \multicolumn{3}{|c|}{ Bloque Temprano de BVS11 } \\
\hline & NISP & $\begin{array}{c}\text { NISP } \\
\text { completos }\end{array}$ & $\begin{array}{c}\% \text { NISP } \\
\text { completos }\end{array}$ & $\begin{array}{l}\text { NISP/ } \\
\text { MNE }\end{array}$ & $\begin{array}{c}\text { NISP } \\
\text { Completos }\end{array}$ & $\begin{array}{c}\% \text { NISP } \\
\text { completos }\end{array}$ & NISP/MNE & $\begin{array}{c}\text { NISP } \\
\text { completos }\end{array}$ & $\begin{array}{c}\% \text { NISP } \\
\text { completos }\end{array}$ \\
\hline Cráneos & 17 & o & ०\% & 10 & o & ०\% & 10 & o & ०\% \\
\hline Mandíbulas & 7,2 & 3 & $2,3 \%$ & 6 & o & ०\% & 2,5 & o & ०\% \\
\hline Atlas/Axis & 1,6 & 7 & $20 \%$ & 1,8 & 1 & $14,3 \%$ & o & o & ०\% \\
\hline V. Cervicales & 3,6 & 11 & $6,1 \%$ & 2,3 & 6 & $16,7 \%$ & 2,2 & $\mathrm{o}$ & ०\% \\
\hline V. Torácicas & 2 & 21 & $15,3 \%$ & 2,8 & 25 & $38,4 \%$ & 1,8 & 4 & $28,6 \%$ \\
\hline V. Lumbares & 3,8 & 10 & $4,7 \%$ & 8,2 & 22 & $11,2 \%$ & 2 & 1 & $7,1 \%$ \\
\hline Escapulas & 3,8 & 1 & $1,1 \%$ & 2,1 & o & ०\% & 2 & o & ०\% \\
\hline Húmeros & 6 & o & ०\% & 4,5 & o & ०\% & 3,7 & o & ०\% \\
\hline Radio-ulnas & 7,2 & o & ०\% & 4,8 & o & ०\% & 2,3 & $\mathrm{o}$ & ०\% \\
\hline Pelvis & 10,2 & o & ०\% & 5,7 & o & ०\% & 1 & o & ०\% \\
\hline Fémures & 10,5 & o & ०\% & 6,4 & o & ०\% & 3,8 & o & ०\% \\
\hline Tibias & 5,8 & o & ०\% & 4,6 & o & ०\% & 2,5 & o & ०\% \\
\hline Metapodios & 8,3 & o & ০\% & 5,9 & o & ०\% & 3,3 & o & ०\% \\
\hline Falanges 1 & 2,4 & 5 & $2,0 \%$ & 2,3 & o & ०\% & 1,6 & o & ०\% \\
\hline
\end{tabular}

Tabla 5. Índice de fragmentación (NISP/MNE) y proporción de elementos completos.

sugerir la intención humana de segmentar estas porciones para extraer la grasa contenida. Asimismo, en la Figura 5 puede apreciarse que aquellos huesos que poseen una mayor recurrencia de negativos de impacto son los que ofrecen algún contenido medular, con independencia de la abundancia de lípidos o de la palatabilidad de la médula. Entonces, el panorama que se observa es un escenario en el cual la región apendicular fue siempre aprovechada de manera integral.

Por lo tanto, la localización y morfología de las huellas de corte y percusión en el esqueleto axial y apendicular, en conjunto con los patrones de fractura, informan que en todos los casos se realizó la trayectoria completa del procesamiento: desde el inicio de la secuencia de desarticulación (separación de la cabeza, espinazo, el costillar y los miembros) hasta los momentos finales relacionados con el trozamiento para el reparto y/o consumo, aprovechamiento de la médula y, probablemente también, de la masa encefálica. Este panorama respalda entonces la idea de que se está tratando con loci de consumo final en los cuales se explotaron todos los productos que brinda el esqueleto axial.

\section{Discusión}

Resulta difícil poder indicar la temporada de muerte de los camélidos a partir de los amplios rangos de edad que pudieron ser identificados. Los únicos casos confiables de estacionalidad son las crías identificadas, dado que considerando que la temporada de parición de los guanacos va de diciembre a mediados de febrero (Raedeke, 1978), la edad de los chulengos hallados en diversos sitios (entre tres y seis meses) indica que fueron capturados durante el otoño/invierno.

Si bien el patrón de mortalidad determinado para cada conjunto muestra perfiles similares, es posible esbozar algunas diferencias. Por un lado, la edad de los individuos 
identificados para los sitios del canal Beagle central concuerda con un modelo del tipo prime dominated (Stiner, 1990). En este sentido, bajo una situación de grupos humanos con alto grado de movilidad, la distancia puede ser un factor crítico que condicione las decisiones sobre qué recursos transportar hacia el campamento base. Por ejemplo, la selección de presas de mayor tamaño sería una estrategia rentable si se considera que el aporte calórico de estos ejemplares es más elevado que el provisto por crías y juveniles. Esta situación tal vez explique el perfil de mortalidad observado en el canal Beagle central, en donde la disponibilidad de guanacos en el espacio habría sido más baja que en Península Mitre, particularmente en lo que respecta a Túnel I. En cambio, el perfil de mortalidad de BVS11 podría ser un indicador de estrategias de captura menos selectivas de individuos a transportar, lo cual es consistente con una mayor disponibilidad del recurso a lo largo del ciclo anual en este sector de la costa sur de Tierra del Fuego.

La consideración de los Índices de Supervivencia y los resultados de las correlaciones entre el MAU\% de cada conjunto y los valores de rendimiento económico muestran diferencias que podrían estar relacionadas con distintas condiciones de transporte. Si bien todos los conjuntos exhiben una mayor frecuencia de porciones con contenido medular, la capa D de Túnel I presenta una completitud anatómica más elevada en comparación con los demás conjuntos que podría remitir a situaciones en las cuales las carcasas habrían ingresado más enteras a las localidades de consumo. Una posible explicación podría hallarse en la dificultad que presenta el entorno de Túnel I para acceder hacia el interior desde la costa, y a la notable importancia que tuvo el consumo de pinnípedos para la economía de quienes ocuparon el sitio. Orquera y Piana (2009) calcularon que el $66 \%$ de las calorías consumidas provenía de la carne y grasa de los pinnípedos, $25 \%$ de moluscos y solo un $5 \%$ de guanacos. Aquí, si los grupos humanos lograron abastecer sus requerimientos nutricionales esenciales desde la costa a un bajo costo y reduciendo el riesgo, una estrategia óptima sería entonces que no siempre hayan dedicado mayores esfuerzos a buscar, transportar y procesar guanacos, sino que estos hayan sido capturados ocasionalmente si se hallaban en la inmediatez del campamento base costero (Vázquez, 2015). Estas situaciones habrían favorecido menores costos de transporte y la concomitante posibilidad de acarrear presas más completas. Es en este sentido que puede entenderse la mayor completitud anatómica de Túnel I si se la compara con las medidas de abundancia de Imiwaia I y BVS11.

En cambio, Imiwaia I no solo presenta un Índice de Supervivencia menor, sino que además las correlaciones entre el MAU\% con las Kcal/h y el MUI fueron negativas y muy significativas. Por lo tanto, los elementos ingresados al sitio pudieron haber resultado de decisiones más selectivas sobre qué porciones transportar y cuáles abandonar en el lugar de matanza. Estas observaciones llaman la atención si se considera que el contexto ambiental de bahía Cambaceres pudo haber propiciado el encuentro relativamente frecuente con el recurso en las inmediaciones de los campamentos bases. La información zooarqueológica, sin embargo, sugiere situaciones de mayor selección de elementos a transportar, quizá con el fin de reducir el paquete transportable y priorizar el acarreo del alimento buscado (al parecer, lípidos). Esto sugiere entonces que los cazadoresrecolectores pudieron haber aumentado las distancias recorridas y el número de presas capturadas, bajo un escenario de mayor planificación y logística en donde la movilidad entre el interior y la costa podría haberse desarrollado bajo rangos de aprovisionamiento amplios hacia el interior de los valles para hallar los recursos. Por otra parte, si bien están representados todos los elementos, las extremidades superiores, medias, inferiores, calcáneos y pies son en general las unidades más abundantes (ver Figura 4); en otras palabras, son más numerosos los elementos que poseen moderado/bajo rendimiento en carne (excepto por los fémures cuyo contenido cárnico es elevado) y que demandan poco tiempo de procesamiento. Si consideramos asimismo que todas las unidades anatómicas que poseen tuétano fueron fragmentadas para su ingesta (ver Tabla 5), y 
que además las correlaciones entre el MAU\% y el Índice de Médula fueron siempre débiles y no significativas estadísticamente, podría plantearse un panorama en el cual el procesamiento y el consumo de lípidos de guanacos fue una actividad extensivamente desarrollada en el sitio. El requerimiento de grasas pudo haber sido un factor clave que primó en las decisiones sobre qué elementos transportar y cuáles abandonar, por lo que no es de extrañar que los huesos largos hayan sido preferentemente seleccionados para tal fin: ofrecen carne, médula y grasa ósea, al mismo tiempo que constituyen buenos soportes para la producción de instrumentos (Christensen y Legoupil, 2014; San Román et al., 2014; Sierpe, 2018). Esto no es un aspecto menor, dado que en los tres conjuntos aquí analizados es común hallar elementos confeccionados sobre las diáfisis de los huesos largos de guanacos.

En cambio, si bien los elementos axiales contienen alto valor en carne, tienen pocos lípidos y carecen de estructura ósea adecuada para la confección de instrumentos. Por lo tanto, esta información sugiere que la selección de porciones anatómicas a transportar pudo depender de la distribución de los productos dentro de las carcasas y de las preferencias alimenticias de los cazadores-recolectores. Se plantea entonces un escenario en el cual las decisiones sobre qué partes transportar parecen haber estado fundadas en el interés por obtener la mayor cantidad de fuentes de grasa animal posible. Éste es un aspecto llamativo si se considera el importante aporte energético provisto por los mamíferos marinos: mientras los camélidos alcanzan un NMI de 14 individuos (ca. 1.096.410 rendimiento en kcal), los pinnípedos suman 32 Arctocephalus australis (ca. 2.048.000 rendimiento en kcal) y cuatro Otaria flavescens ${ }^{1}$, al tiempo los peces son los taxones más abundantes (en términos de NISP) y la presencia de las aves no es nada despreciable (Martinoli, 2015). Esto sin considerar un posible aporte de cetáceos (ver Tabla 1). Por ello, cabe preguntarse entonces ¿Qué motivó la búsqueda y consumo de guanacos, incluso en espacios posiblemente alejados de la costa dentro de un contexto en el cual los pinnípedos constituyeron el principal aporte alimenticio y en donde, además, no existieron armas específicas para cazar guanacos, sino tecnología especializada para capturar mamíferos marinos (e.g. arpones de punta desmontable)?

Aquí es necesario considerar que la dependencia de cierto tipo de recursos (como, en este caso, los pinnípedos) tiene como consecuencia que, ante una escasez periódica de estos animales o bajo eventuales fluctuaciones impredecibles en el ambiente, los cazadores-recolectores deban ejecutar estrategias alternativas para suplir el déficit alimenticio. Estas oscilaciones pueden ser estacionales, o bien durar breves o largos períodos de tiempo. En este sentido, los perfiles de edad y sexo determinados para los restos de Arctocephalus australis provenientes de la capa $\mathrm{D}$ de Túnel I indican que las cacerías de estas presas se desarrollaron fundamentalmente entre los meses de marzo a septiembre (Orquera y Piana, 1999; Schiavini, 1990, 1993) $)^{2}$. Ante estas situaciones es factible pensar que los cazadores-recolectores por momentos hayan resuelto mitigar esta carencia periódica incorporando tácticas alternativas para minimizar el riesgo a la escasez, sin que esto implique giros sustanciales en los modos de subsistencia y organización laboral. Por lo tanto, si se presume que las cacerías de pinnípedos habrían ocurrido principalmente durante el invierno (Shiavini, 1990, 1993), entonces sería lógico pensar que los grupos humanos enfrentaron mayores condiciones de estrés energético durante la época estival. Aunque las temperaturas fueron menos rigurosas en esta época del año, la ingesta de fuentes de energía habría sido igualmente necesaria. Este panorama pudo promover la reorientación de las áreas de captación de recursos hacia el interior para obtener guanacos y compensar así la carencia de grasas. Al mismo tiempo, la planificación de las cacerías así planteada también tiene la ventaja de que es precisamente en verano cuando los camélidos se encuentran en mejor estado nutricional (Raedeke, 1978), idóneo para el desarrollo de las prácticas cinegéticas sobre este recurso. Esta posibilidad de partidas de caza estacionales no sólo explicaría el hecho de que en Imiwaia I los cazadores-recolectores se estén desplazando
1. No se disponen de datos sobre el rendimiento en kilocalorías para Otaria flavescens.
2. Estos resultados se desprenden del análisis efectuado sobre la estacionalidad de muerte establecida mediante cortes delgados de dientes, los cuales indican capturas principalmente de machos en el mar desagregados de las colonias (Schiavini, 1990, 1993): terminada la concentración estival en las colonias de reproducción, los machos se dispersan de inmediato y penetran al canal Beagle en busca de alimento, mientras que las hembras con las crías permanecen en o cerca de las colonias con sus crías. 
3. Esto no implica la ausencia de cacerías orientadas a la captura de pinnípedos en el mar. De hecho, tanto Vidal (1988) como Zangrando, Tessone y Vázquez (2009) han observado similitudes ergológicas entre BVS11 y los conjuntos del canal Beagle central que pueden corresponderse a la ejecución de similares técnicas de captura de pinnípedos en el mar. más allá de las adyacencias inmediatas al campamento base, sino que también podría dar cuenta del desarrollo de intensas técnicas extractivas, tal y como lo expresa la preparación de la grasa ósea identificada para el Segundo Componente de Imiwaia I (ver discusión en Alunni, 2018b).

El Bloque Temprano de BVS11 plantea un contexto de discusión diferente, dado que la proporción de pinnípedos y guanacos es similar en términos de NMI: los primeros alcanzan un NMI de tres Arctocephalus australis (que representan ca. 192.000 rendimiento en kcal) y tres Otaria flavescens (Martinoli, 2018), mientras que el NMI de guanacos es de cinco (que representan ca. $391.575 \mathrm{kcal}$ respectivamente). No obstante, para este sitio resulta difícil realizar deducciones sobre las pautas de aprovechamiento de guanacos dado que los datos obtenidos a partir de los Índices de Supervivencia y de las correlaciones entre el MAU\% y los índices de rendimiento son ambiguos: mientras los índices de Supervivencia muestran una mayor abundancia de miembros delanteros y traseros (ver Figura 4), los resultados de las covarianzas no sugieren conductas de transporte selectivas a favor de estos elementos (ver Tabla 4). Es posible que la menor extensión de la superficie excavada $\left(2 \mathrm{~m}^{2}\right)$ y el número de restos obtenidos no sean lo suficientemente representativos para realizar interpretaciones confiables. Es por este motivo que, de momento y a modo exploratorio, se propone que la ausencia de un patrón de mortalidad definido (ver Figura 3), en conjunto con falta de correlaciones estadísticamente significativas entre los índices de rendimiento y el MAU\%, podrían ser indicadores del ingreso de individuos de diversos tamaños y de carcasas relativamente enteras a las bases residenciales. De corroborarse este supuesto, una posible explicación podría hallarse en el acceso continuo a los recursos de importancia económica: dada su disponibilidad, tanto los guanacos como los pinnípedos pudieron haber sido capturados en tierra desde las costas. Esto habría permitido a los cazadores-recolectores procurarse de los nutrientes esenciales para la dieta (proteínas y grasas) con cierta continuidad y predictibilidad dentro del entorno inmediato sin la necesidad de movilizarse a grandes distancias para lograr obtenerlos ${ }^{3}$. Dicha cercanía pudo haber propiciado desplazamientos cercanos a los espacios de residencia para capturar guanacos y transportar sus carcasas sin selección de unidades anatómicas. En este sentido, los patrones conductuales relacionados con el aprovechamiento de este recurso pudieron haber perseguido una estrategia similar a la planteada para Túnel I, en la medida que el uso de los guanacos habría sido oportunista siempre que pudieran ser interceptados en los sectores de playas. En el futuro, estos supuestos deberán ser corroborados por medio de muestras más amplias a las actualmente disponibles para el Bloque Temprano de BVS11.

Por lo tanto, los datos presentados y discutidos no acompañan los patrones conductuales esperados según la disponibilidad estacional y espacial de los guanacos. Como expectativa, se esperaba que los rangos de aprovisionamiento disminuyeran hacia la zona oriental del canal Beagle y Península Mitre, en función de la supuestamente mayor presencia del recurso hacia estos tramos costeros. Sin embargo, se observa que en entornos tan distintos como el que exhiben sector occidental del canal Beagle y Península Mitre el aprovechamiento de los guanacos pudo haber sido oportunista y dependiente de su encuentro en las cercanías de las franjas litorales. A diferencia de Península Mitre, donde la disposición de camélidos no habría tenido diferencias estacionales muy marcadas, en Túnel I la explotación de estos animales pudo haberse desarrollado sobre todo en el invierno, momento en que bajan a las costas y pueden ser interceptados con mayor frecuencia. En Imiwaia I, en cambio, pese a la relativa facilidad que exhibe el entorno de bahía Cambaceres para comunicar la costa con el interior y al potencial incremento de guanacos hacia el invierno, se deduce que estos habrían sido buscados en distintos períodos del año. La cacería de camélidos durante la época estival, momento en que estos se hallan principalmente en las zonas altas, pudo haber derivado en la necesidad de fraccionar la carcasa para transportar la mayor cantidad de los 
nutrientes más deseados. De acuerdo con los análisis aquí efectuados sobre las medidas de abundancia anatómica y los patrones de procesamiento, es posible suponer que la grasa animal habría sido la fuente más buscada. En resumidas palabras, se observa entonces que la mera disposición espacial y estacional de los guanacos no explica los patrones observados en el registro zooarqueológico, y que probablemente las pautas conductuales de los cazadores-recolectores sean resultado de diversas contingencias o requerimientos nutricionales según los distintos casos.

\section{Conclusión}

Al comienzo de este trabajo se mencionó que los guanacos como recurso fueron considerados como complementos para la dieta de los cazadores-recolectores costeros que habitaron el sur de Tierra del Fuego durante el Holoceno medio. Sin embargo, los resultados aquí discutidos expresan variabilidad espacial en sus pautas de aprovisionamiento, lo que invita a repensar el rol que desempeñó el ámbito terrestre para la economía de los grupos humanos que habitaron esta región durante los momentos más tempranos de la secuencia ocupacional.

Por un lado, la explotación de guanacos en la capa D de Túnel I apoya la existencia de un consumo más oportunista, el cual habría implicado que las presas fueran capturadas en áreas cercanas a los emplazamientos costeros. Esto no desmerece la importancia de las grasas de camélidos, cuyo contenido dentro de las distintas secciones del esqueleto pudo haber conducido a situaciones de selección a favor de ciertos elementos ricos en lípidos, particularmente en épocas invernales. En el Segundo Componente de Imiwaia I los mamíferos marinos continúan siendo el principal componente dietario, pero las incursiones hacia el interior en ocasiones parecen haber involucrado rangos espaciales de aprovisionamiento más extensos, lo que implica escenarios de mayor planificación de las cacerías (quizá estacionales, orientadas fundamentalmente hacia la época estival). Además, en comparación con Túnel I, la mayor importancia del ámbito terrestre para los ocupantes de Imiwaia I es evidente si se considera el incremento en la abundancia taxonómica de guanacos que expresa su conjunto faunístico. Es posible que la facilidad que ofrece el entorno terrestre de Cambaceres para transitar hacia el interior haya propiciado no sólo un aumento en el consumo de camélidos, sino también desplazamientos más amplios hacia el interior para su captura. Esto puede ser visto desde el punto de vista del perfil anatómico, el cual expresa en Imiwaia I situaciones de mayor selección de partes que en Túnel I, lo que suele ser interpretado como resultado de distancias más grandes entre las localidades de matanza y consumo final. En cambio, en Península Mitre el uso de ámbitos terrestres y los recursos allí disponibles pudo ser más oportunista e integrado al aprovisionamiento de recursos litorales.

\section{Agradecimientos}

Este trabajo fue financiado por el PICT 2013-1011 (Dir. Atilio F. Zangrando). Agradecemos a los evaluadores anónimos cuyos comentarios han permitido mejorar el contenido de este trabajo. 


\section{Q Referencias citadas}

»Alunni, D. V. (2016). Transporte y consumo de guanacos por cazadores-recolectores marítimos del canal Beagle durante el Holoceno medio: El caso de Imiwaia I. Intersecciones en antropología, 17(2), 251-261.

"Alunni, D. V. (2018a). Estrategias de aprovisionamiento de guanacos y uso del bosque Magallánico por cazadores-recolectores costeros. Revista del Museo de Arqueología, 11(2), 7-22.

"Alunni, D. V. (2018b). El uso de guanacos por cazadores-recolectores de la costa sur de Tierra del Fuego: pautas de aprovechamiento y estudios tafonómicos. (Tesis Doctoral inédita), Universidad de Buenos Aires, Argentina.

»Alunni, D. y Zangrando, A. F. (2012). Primeros datos sobre el transporte, procesamiento y consumo de guanacos en la localidad arqueológica Heshakaia (sudeste de Tierra del Fuego, Argentina). Magallania, 40(1), 319-331.

" Behrensmeyer, A. K. (1978). Taphonomic and ecologic information from bone weathering. Paleobiology, 4(2), 150-162.

» Bettinger, R. L. (1991). Hunter-gatherers. Archaeological and evolutionary theory. Nueva York: Plenum Press.

"Binford, L. R. (1978). Nunamiut Ethnoarchaeology. Nueva York: Academic Press.

" Binford, L. R. (1981). Bones, ancient men and modern myths. Nueva York: Academic Press.

» Bjerck, H. B., Zangrando, A. F., Breivik, H. M., Piana, E. y Negre, J. (2016). Marine Ventures: The Cambaceres Surveys, Tierra del Fuego, Argentina. Informe al NTNU Vitenskapsmuseet arkeologisk. Manuscrito inédito.

»Borrero, L. A. (1990). Fuego-Patagonian bone assemblages and the problem of communal guanaco hunting. En L. B. Davis y B. O. Reeves (Eds.), Hunters of the recent past (pp. 373399). Londres: Unwin Hyman.

»Borrero, L. A. (2007). Longitudinal taphonomic studies in Tierra del Fuego, Argentina. En M. A. Gutierrez, L Miotti, G. Barrientos, G. Mengoni Gonalons y M. Salemme (Eds.), Taphonomy and Zooarchaeology in Argentina (pp. 219-233). Oxford: BAR International Series 1601.

" Borromei, A. M., Coronato, A., Quattrocchio, M., Rabassa, J., Grill, S. y Roig, C. (2007). Late Pleistocene-Holocene environments in Valle Carbajal, Tierra del Fuego, Argentina. Journal of South American Earth Sciences, 23(4), 321-335.

» Bunn, H. T., Bartram, L. E. y Kroll, E. M. (1988). Variability in bone assemblage formation from Hadza hunting, scavenging, and carcass processing. Journal of Anthropological Archaeology, 7(4), 412-457.

»Cannon, M. D. (2003). A model of central place forager prey choice and an application to faunal remains from the Mimbres Valley, New Mexico. Journal of Anthropological Archaeology, 22(1), 1-25.

"Christensen, M. y Legoupil, D. (2014). Materias óseas y cadena operativa en Patagonia Austral: el caso del sitio Offing (estrecho de Magallanes). Trabajo presentado en las IX Jornadas de Arqueología en la Patagonia. Coyhaique, Chile.

»De Lamo, D. A. (1990). Determinación de edad en guanacos (Lama guarnicoe Müller) por análisis del desarrollo y desgaste dentario. Veterinaria argentina, 7(69), 621-626. 
" De Nigris, M. E. (2004). El consumo en grupos cazadores recolectores. Un ejemplo zooarqueológico de Patagonia meridional. Buenos Aires: Sociedad Argentina de Antropología.

»De Nigris, M. E. y Mengoni Goñalons, G. L. (2004). El guanaco como fuente de carne y grasas en Patagonia. En M. T. Civalero, P. M. Fernández y A. G. Guráieb (Eds.). Contra viento y marea. Arqueología de Patagonia (pp. 469-476). Buenos Aires: Instituto Nacional de Antropología y Pensamiento Latinoamericano.

»Elkin, D. C. (1995). Volume density of South American camelid skeletal parts. International Journal of Osteoarchaeology, 5(1), 29-37.

»Estévez Escalera,J.y Mameli, L.(2000). Muerte en el canal: experiencias bioestratigráficas controladas sobre la acción sustractiva de cánidos. Archaeofauna. International Journal of Archaeozoology, 9, 7-16.

"Faith, J. T. y Gordon, A. D. (2007). Skeletal element abundances in archaeofaunal assemblages: economic utility, sample size, and assessment of carcass transport strategies. Journal of Archaeological Science, 34(6), 872-882.

" Fernández, M., Ponce, F. J., Zangrando, A. F., Borromei, A. M., Musotto, L. L., Alunni, D. V. y Vázquez, M. (en prensa). Relationships between terrestrial animal exploitation, marine hunter-gatherers and palaeoenvironmental conditions during the Middle-Late Holocene in the Beagle Channel region (Tierra del Fuego). Quaternary International. https://doi.org/10.1016/j.quaint.2018.05.032

» Gamble, C. (1990). El poblamiento paleolítico de Europa. Barcelona: Crítica.

" Gifford-Gonzalez, D. (1989). Ethnographic analogues for interpreting modified bones: some cases from East Africa. En R. Bonnichsen y H. Sorg (Eds.), Bone modification (pp. 179-246). Orono: Center for the Study of the First Americans, Institute for Quaternary Studies, University of Maine.

" Gusinde, M. 1986 (1937). Los Indios de Tierra del Fuego. Tomo segundo: Los Yámanas. Buenos Aires: Centro Argentino de Etnología Americana.

" Heane, E., Cavagnaro, F. P., Zangrando, A. F. y Crojetovich, A. D. (2011). Relevamiento arqueológico. Relevamiento de la Estancia Moat, Provincia de Tierra del Fuego, Antártida e Islas del Atlántico Sur (República Argentina). Informe presentado al Programa refugios de la Vida Silvestre. Tierra del Fuego, Ushuaia. Manuscrito inédito.

" Heusser, C. L. (2003). Ice Age Southern Andes. A chronicle of paleoecological events. Developments in Quaternary Science 3. Amsterdan: Elsevier.

» Johnson, E. (1985). Current developments in bone technology. Advances in Archaeological Method and Theory, 8, 157-235.

» Kaufmann, C. (2009). Estructura de edad y sexo en guanaco. Estudios actualísticos y arqueológicos en Pampa y Patagonia. Buenos Aires: Sociedad Argentina de Antropología.

» Kelly, R. L. y Todd, L. C. (1988). Coming into the country: Early Paleoindian hunting and mobility. American Antiquity, 53(2), 231-244.

» Klein, R. G. y Cruz-Uribe, K. (1984). The Analysis of Animal Bones from Archaeological Sites. Chicago: University of Chicago Press.

»Legoupil, D. y Fontugne, M. (1997). El Poblamiento Marítimo en los Archipiélagos de Patagonia: Núcleos Antiguos y Dispersión Reciente. Anales del Instituto de la Patagonia, $25,75-87$.

» L'Heureux, L. y Kaufmann, C. (2012). Estimación de la edad de muerte de guanacos juveniles a partir de las dimensiones de los huesos largos no fusionados: Estructura de edad y estacionalidad en el campo volcánico de Pali Aike (sitio Orejas de Burro 1). Magallania, 40(2), 151-220. 
" Lupo, K. D. (2006). What explains the carcass field processing and transport decisions of contemporary hunter-gatherers? Measures of economic anatomy and zooarchaeological skeletal part representation. Journal of Archaeological Method and Theory, 13(1), 19-66.

" Lupo, K. D. (2007). Evolutionary foraging models in zooarchaeological analysis: recent applications and future challenges. Journal of archaeological research, 15(2), 143-189.

» Lyman, R. L. (1987). Archaeofaunas and butchery studies: a taphonomic perspective. En M. Schiffer (Ed.), Advances in Archaeological Method and Theory (pp. 249-337). Nueva York: Academic Press.

" Lyman, R. L. (1994). Vertebrate Taphonomy. Cambridge: Cambridge University Press.

" Marean, C. W. y Cleghorn, N. (2003). Large mammal skeletal element transport: applying foraging theory in a complex taphonomic system. Journal of taphonomy, 1(1), 15-42.

" Martin, F. M. (1998). Madrigueras, dormideros y letrinas: Aproximación a la tafonomía de zorros. En L. A. Borrero (Ed.), Arqueología de la Patagonia Meridional (Proyecto Magallania) (pp. 73-96). Buenos Aires: Búsqueda.

»Martinoli, M. P. (2015). Procesamiento y consumo de pinnípedos: el caso de las ocupaciones canoeras tempranas del sitio Imiwaia I (Tierra del Fuego, República Argentina). Intersecciones en antropología, 16(2), 367-381.

»Martinoli, M.P.(2018). Modalidades de explotación, procesamientoy consumo de pinnípedos en la margen meridional de Tierra del Fuego. (Tesis Doctoral inédita), Universidad de Buenos Aires, Argentina.

» Mengoni Goñalons, G. L. (1996). La domesticación de los camélidos sudamericanos y su anatomía económica. En D. Elkin, C. Madero, G. Mengoni Goñalons, D. Olivera, M. Reigadas y H. Yacobaccio (Eds.), Zooarqueología de Camélidos. Perspectivas Teóricas y Metodológicas (Volumen II, pp. 3-45). Buenos Aires: Grupo Zooarqueología de Camélidos.

» Merino, M. L. y Cajal, J. L. (1993). Estructuras sociales de la población de guanacos (Lama guanicoe, Müller 1776) en la costa norte de Península Mitre. Tierra del Fuego. Argentina. Studies on Neotropical Fauna and Enviroment, 28(3), 129-138.

» Metcalfe, D. y Barlow, B. K. (1992). A model for exploring the optimal trade-off between field processing and transport. American Anthropologist, 94, 340-359.

» Montes, C., De Lamo, D. A y Zavatti, J. (2000). Distribución de abundancias de guanacos (Lama guanicoe) en los distintos ambientes de Tierra del Fuego, Argentina. Mastozoología Neotropical, 7(1), 23-31.

»Morlan, R. E. (1984). Toward the Definition of Criteria for the Recognition of Artificial Bone Alterations. Quaternary Research, 22(2), 160-171.

"Ocampo, E. y Rivas, H. (2004). Poblamiento temprano de los extremos geográficos de los canales patagónicos: Chiloé e Isla Navarino 1. Chungará. Revista de Antropología Chilena, 36, 317-331.

» Oporto, N., Bigatti, R. y Larrieu, E. (1979). Determinación de edades en guanaco (Lama guanicoe) en base a su dentición. Revista Argentina de Producción Animal, 4(9), 965-983.

» Orians, G. H. y Pearson, N. (1979). On the theory of central place foraging. En D. J. Horn, G. R. Stairs y R. D. Mitchell (Eds.), Analysis of Ecological Systems (pp. 155-178). Columbus: Ohio State University Press.

" Orquera, L. A.yPiana, E. L.(1986-1987).Composición tipológicay datos tecnomorfológicos y tecnofuncionales de los conjuntos arqueológicos del sitio Túnel I, Tierra del Fuego. Relaciones de la Sociedad Argentina de Antropología, XVII, 201-239. 
" Orquera, L. A. y Piana, E. L. (1988). Human littoral adaptation in the Beagle Channel region: the maximum possible age. Quaternary of South America and Antarctic Peninsula, 5(1987), 133-65.

» Orquera, L. A. y Piana, E. L. (1999). Arqueología de la región del canal Beagle (Tierra del Fuego, República Argentina). Buenos Aires: Sociedad Argentina de Antropología.

》 Orquera, L. A. y Piana, E. L. (200o). Imiwaia I: un sitio de canoeros del sexto milenio AP en la costa norte del canal Beagle. En J. B. Belardi, F. Carballo y S. Espinosa (Eds.), Desde el país de los gigantes. Perspectivas arqueológicas en Patagonia (Volumen 2, pp. 441-453). Rio Gallegos: Universidad Nacional de la Patagonia Austral.

" Orquera, L. A. y Piana, E. L. (2009). Sea nomads of the Beagle Channel in Southernmost South America: over six thousand years of coastal adaptation and stability. The Journal of Island and Coastal Archaeology, 4(1), 61-81.

» Puig, S. y Monge, S. (1983). Determinación de la edad en Lama guanicoe (Müller). Deserta, 7, 246-270.

» Raedeke, K. (1978). El guanaco de Magallanes. Chile. Su distribución y biología. Informe presentado al CONAF. Manuscrito inédito.

"San Román, M., Christensen, M., Legoupil, D., Sierpe, V., Martin, F. y Morello, F. (2014). Guanacos onboard: Camelid transport and processing by Marine Hunters in Patagonia, Chile. Trabajo presentado en el $12^{\text {th }}$ Internacional Council for Archaeozoology. San Rafael, Argentina.

"Scheinsohn, V. (2010). Hearts and Bones: Bone Raw Material Exploitation in Tierra del Fuego. Oxford: BAR International Series 2024.

"Schiavini, A. (1990). Estudio de la relación entre el hombre y los pinnípedos en el proceso adaptativo humano al canal Beagle, Tierra del Fuego, Argentina. (Tesis Doctoral inédita). Universidad de Buenos Aires, Argentina.

"Schiavini, A. (1993). Los lobos marinos como recurso para cazadores-recolectores marinos: el caso de Tierra del Fuego. Latin American Antiquity, 4(4), 346-366.

"Shipman, P. (1981). Applications of scanning electron microscopy to taphonomic problems. En A. M. Cantwell, J. B. Griffin y N. A. Rothschild (Eds.), The research potential of anthropological museum collections (pp. 357-385). Nueva York: New York Academy of Sciences.

» Sierpe, V. (2018). Differential exploitation of artiodactyls between marine hunter-gatherers of the Middle and Late Holocene of the south-central continental coast of the Strait of Magellan, Patagonia Chile. Trabajo presentado en el XVIII Congreso UISPP. París, Francia.

"Smith, E. A. (1983). Anthropological applications of optimal foraging theory: a critical review. Current Anthropology, 24, 625-651.

"Soulier, M. C. y Costamagno, S. (2017). Let the cutmarks speak! Experimental butchery to reconstruct carcass processing. Journal of Archaeological Science: Reports, 11, 782-802.

» Stiner, M. C. (1990). The use of mortality patterns in archaeological studies of hominid predatory adaptations. Journal of Anthropological Archaeology, 9(4), 305-351.

"Stiner, M. C. (1994). Honor among thieves: A zooarchaeological study of Neandertal ecology. Princeton: Princeton NJ.

"Stiner, M. C. y Munro, N. D. (2002). Approaches to prehistoric diet breadth, demography and prey ranking systems in time and space. Journal of Archaeological Method and Theory, 9, 175-208. 
"Ugan, A. (2005). Does size matter? Body size, mass collecting, and their implications for understanding prehistoric foraging behaviour. American Antiquity, 70, 75-89.

» Vázquez, M. (2015). Guanacos en el segundo componente de Túnel I (Cabal Beagle): Un enfoque tafonómico. Magallania, 43(1), 251-277.

» Vázquez, M., Zangrando, A. F., Tessone, A., Ceraso, A. y Sosa, L. (2007). Arqueología de bahía Valentín (península Mitre, Tierra del Fuego): Nuevos resultados y perspectivas. En F. Morello, M. Martinic, A. Prieto y G. Bahamonde (Eds.), Arqueología de FuegoPatagonia. Levantando piedras, desenterrando huesos... y develando arcanos (pp. 755-766). Punta Arenas: CESQUA.

"Vidal, H. (1988). Bahía Valentín: 6000 años de ocupaciones humanas en el oriente fueguino. Trabajo presentado en el IX Congreso Nacional de Arqueología Argentina. Buenos Aires, Argentina.

"Zangrando, A. F. (2009). Historia evolutiva y subsistencia de cazadores-recolectores marítimos de Tierra del Fuego. Buenos Aires: Sociedad Argentina de Antropología.

» Zangrando, A. F., Borrazzo, K. B., Tivoli, A. M., Alunni, D. V. y Martinoli, M. P. (2013). El sitio Heshkaia 35: nuevos datos sobre la arqueología de Moat (Tierra del Fuego, Argentina). Revista del Museo de Antropología, 7(1), 11-24.

» Zangrando, A. F. J., Ponce, J. F., Martinoli, M. P., Montes, A., Piana, E., \& Vanella, F. (2016). Palaeogeographic changes drove prehistoric fishing practices in the Cambaceres Bay (Tierra del Fuego, Argentina) during the middle and late Holocene. Environmental Archaeology, 21(2), 182-192.

»Zangrando, A. F., Tessone, A. y Vázquez, M. (2009). El uso de espacios marginales en el archipiélago fueguino: implicaciones de la evidencia arqueológica de bahía Valentín. En M. Salemme, F. Santiago, M. Álvarez, E. Piana, M. Vázquez y E. Mansur (Eds.), Arqueología de la Patagonia. Una mirada desde el último confín (pp. 47-62). Ushuaia: Utopías. 